This is the accepted manuscript version of the following article:

Kubilay, A., \& Allegrini, J. (2017). Rain sheltering analysis in semi-outdoor environments: case study on passenger comfort in a railway station shelter. Journal of Building

Performance Simulation. http://doi.org/10.1080/19401493.2017.1407825

\title{
Rain sheltering analysis in semi-outdoor environments: case study on passenger comfort in a railway station shelter
}

\author{
A. Kubilay $^{a, b, *}$, J. Allegrini $^{a, b}$ \\ ${ }^{a}$ Laboratory for Multiscale Studies in Building Physics, Swiss Federal Laboratories for Materials Science and \\ Technology (Empa), Dübendorf, Switzerland \\ ${ }^{b}$ Chair of Building Physics, Swiss Federal Institute of Technology ETHZ, Zurich, Switzerland \\ * Corresponding author: Aytaç Kubilay, Laboratory for Multiscale Studies in Building Physics, Swiss Federal \\ Laboratories for Materials Science and Technology (Empa), Überlandstrasse 129, CH-8600, Dübendorf,
} Switzerland. Tel.: +41 58765 4276; E-mail address: aytac.kubilay@empa.ch

\begin{abstract}
Wind-flow field around a semi-outdoor structure can differ significantly from the one around a building. As a result, the design of such a structure can have a strong impact on the rain exposure. This paper studies the winddriven rain sheltering for a prototype of a small railway station shelter designed for rural areas. Computational fluid dynamics (CFD) simulations of wind-driven rain are performed based on an Eulerian multiphase model. A new metric called "wetting ratio" is proposed, which allows for quantitative analysis of wetting due to rain within a volume in the air. The rain exposure of standing passengers is discussed for a range of meteorological conditions based on the yearly climate data. The analyses indicate the critical meteorological conditions and orientations that lead to the highest rain exposure. It is found that minor geometrical modifications, such as side window length, can have a significant impact on the rain exposure.
\end{abstract}

Keywords: Wind-driven rain, Rain sheltering, Rain exposure, Railway station, Computational fluid dynamics (CFD), Eulerian multiphase model

\section{Introduction}

Passengers are exposed to the exterior environment at small railway stations without indoor waiting halls. Such railway stations can mainly be found in rural areas or close to small villages. In addition, low frequency of regional trains that stop at small railway stations can lead to long waiting times. Therefore, shelters are built at small stations to protect passengers from undesired environmental effects that can lower comfort, e.g. wind, rain and sun. However, the majority of shelters and roof structures are built considering only vertical rainfall without taking wind flow into account. Wind-driven rain (WDR) is the type of rainfall which has a horizontal velocity due to the effect of wind flow occurring at the same time. Wetting due to WDR is governed by a wide range of parameters, such as building geometry, environment topography, wind speed, wind direction, rainfall intensity and raindrop-size distribution (Blocken and Carmeliet 2002). As a result, in certain cases, local wind-flow 
patterns due to the presence of the shelter itself can further accelerate raindrops towards the sheltered area, leading to discomfort for passengers.

Moisture due to WDR can lead to undesired phenomena that influence the hygrothermal performance and the durability of building facades. Therefore, a significant number of WDR research focuses on WDR impinging on building surfaces with an aim to analyze the amount of rain penetration in porous building materials (Blocken et al. 2007a; Abuku et al. 2009a) and surface deterioration (Etyemezian et al. 2000; van Mook 2002; Tang and Davidson 2004). Past research indicates that a building has an impact on its own WDR exposure due to the obstruction caused on wind flow by the building itself (Blocken and Carmeliet 2006). Similarly, in multibuilding environments, the wind-flow pattern around a building is further influenced by other buildings. In turn, the presence of neighboring buildings influence the WDR exposure on each other (Blocken et al. 2009; Kubilay et al. 2014, 2015b). In addition to the large-scale influences of building size and shape and of surrounding environment, several studies show also a significant influence of small-scale facade features such as roof overhang (Blocken and Carmeliet 2007; Abuku et al. 2009b; Foroushani et al. 2014; Kubilay et al. 2017; Ge et al. 2017), cornices (Hangan 1999), window sills and balconies (Kubilay et al. 2017), recessed facade (Briggen et al. 2009).

While past research on WDR discusses extensively the rain exposure and rain sheltering on building facades, the number of studies for pedestrian rain comfort within semi-outdoor environments is limited. Wind-flow field around a structure such as a railway station shelter differs significantly from the one around a building. Furthermore, to the best knowledge of the authors, there are no criteria in the literature for rain comfort of pedestrians in a similar way to the wind comfort (NEN 8100 2006) or thermal comfort (Fiala et al. 2012) criteria. Persoon et al. (2008) use numerical WDR simulations to show that certain roof types in 2D football stadia can lead to particular wind-flow patterns that help to improve the conditions around spectator seats during rainfall. Van Hooff et al. (2011) compare rain sheltering in various 3D stadia configurations and roof types. Wu and Kriksic (2012) present a rain sheltering study around a transit bus shelter as an example of numerical studies for pedestrian comfort. However, the reported results are very limited in terms of meteorological conditions. Kubilay (2014) performs a study of rain sheltering of an urban public transport station for buses, trams and trains that consists of several roofs with complex geometries. The results suggest that raindrops can travel further under the roof due to the acceleration of wind caused by the roof itself.

The rain sheltering studies mentioned above compare the sheltering efficiency for various case studies mostly based on the amount of surface wetting and, in some cases, consider a surface either totally wet or totally dry. One possible reason for that is the majority of the computational fluid dynamics (CFD) simulations of WDR is based on a Lagrangian particle tracking (LPT) model (Choi 1991, 1994; Blocken and Carmeliet 2002), where trajectories for individual raindrops are obtained by solving their equation of motion. Analysis of rain sheltering based on the wetting amount within a volume of air can provide a better insight in semi-outdoor environments. However, it is difficult to take into account the existing amount of different raindrop sizes in the air with the LPT models. In this regard, Eulerian multiphase (EM) models (Huang and Li 2010; Kubilay et al. 2013, 2014, 2015b; Wang et al. 2015) can be a better alternative. In the EM models, rain is regarded as a continuum, similar to the 
gas phase, i.e. air. Separate continuity and momentum equations are solved for each raindrop size, which give the distribution of rain fraction and rain velocity everywhere in the computational domain. The EM model also allows for faster analysis on all surfaces in the domain, especially for structures with fine details (Kubilay et al. 2017).

In the present paper, CFD simulations of WDR are performed based on an EM model in order to analyse rain infiltration within a prototype of a shelter design based on which Allegrini and Kubilay (2017) performed a wind comfort study. It is aimed to determine the critical meteorological conditions for the passengers in such a semioutdoor geometry. To achieve this, a new metric called wetting ratio is introduced. Wetting ratio is similar to the commonly-used catch ratio, but allows for a volumetric analysis of rain sheltering by considering the raindrop velocity in the air, which then can be used in combination with meteorological data. This new metric is demonstrated on the rain sheltering performance of the prototype for various meteorological conditions and orientations. The influence of small geometrical modifications on rain sheltering is studied. The prediction of rain exposure could have a large impact, because shelters with the same design are planned to be installed at a large number of railway stations. In the following, section 2 describes the case study for the WDR analysis. Section 3 presents the numerical models for wind and WDR simulations, the computational domain, grid and the boundary conditions. Section 4 presents the meteorological data and the simulation settings. Section 5 presents the simulation results and the main findings of the study. Finally, sections 6 and 7 provide discussion and conclusion, respectively.

\section{Description of the case study}

The geometry for the prototype of a railway station shelter design is given in Fig. 1. The prototype was designed to be installed at small railways stations in Switzerland. The shelter prototype was designed by Swiss Federal Railways (SBB) and the design is their intellectual property. Fig. 1 shows a slightly simplified geometrical model in order to avoid fine grid cells necessary to resolve the flow around small details included in the initial model, e.g. metal bolts, window frames. The shelter prototype consists of a sheet metal construction. The side and back walls are made out of glass (blue in Fig. 1). The shelter is $4.8 \mathrm{~m}$ long, $1.5 \mathrm{~m}$ wide and the distance from the ground to the bottom side of the roof is $2.7 \mathrm{~m}$. There is a vertical clearance from the ground to the seats along the side and back windows of the shelter. The purpose of the vertical clearance is to avoid collection of leafs and litter in the waiting area and to help maintenance. The area below the roof is divided into two parts by the support structure. On the smaller side of the prototype the ticket machine is mounted on the support structure. The other side is the waiting area for passengers. The waiting area is protected from the wind and rain by the side and back windows. The side window covers only the half of the shelter with a width of $0.75 \mathrm{~m}$. An information screen is mounted at the support structure within the waiting area (black in Fig. 1). Four seats are installed in the sheltered area and there is some more space for passengers standing below the roof on both sides of the support structure. On one hand, the shelter aims to provide rain sheltering for passengers and the ticket machine. On the other hand, the design is chosen to provide the feeling of being in an open area to the waiting passengers. Hence, for example, the side window has not the full width of the roof in the original design. 


\section{Numerical model for WDR}

\subsection{Governing equations}

In the present study, 3D steady Reynolds-averaged Navier-Stokes (RANS) CFD simulations with the realizable $k$ - $\varepsilon$ model (Shih et al. 1995) are used for the incompressible wind flow. The realizable $k-\varepsilon$ model satisfies the mathematical constraints on turbulent stresses, i.e. the normal stresses are positive and the shear stresses satisfy the Schwarz inequality. Furthermore, it also attenuates the stagnation point anomaly, which improves the results in the wake compared to the standard $k-\varepsilon$ model (Launder and Spalding 1974). The realizable $k-\varepsilon$ model was also used in various validation studies of WDR models and resulted in accurate distribution of WDR intensity on building facades (Blocken and Carmeliet 2007; Briggen et al. 2009).

The governing equations for WDR are based on an Eulerian multiphase (EM) model (Huang and Li 2010; Kubilay et al. 2013). In the Eulerian multiphase (EM) model for WDR, rain phases are considered as continuum, similar to the air phase. Each class of raindrop size is treated as a different rain phase, as each group of raindrops with similar size will interact with the wind-flow field in a similar way. For each separate rain phase, the following continuity and momentum equations are solved (Kubilay et al. 2013):

$$
\begin{aligned}
& \frac{\partial \alpha_{\mathrm{d}}}{\partial t}+\frac{\partial \alpha_{\mathrm{d}} \overline{u_{\mathrm{d}, \mathrm{j}}}}{\partial x_{\mathrm{j}}}=0 \\
& \frac{\partial \alpha_{\mathrm{d}} \overline{u_{\mathrm{d}, \mathrm{i}}}}{\partial t}+\frac{\partial \alpha_{\mathrm{d}} \overline{u_{\mathrm{d}, \mathrm{i}}} \overline{u_{\mathrm{d}, \mathrm{j}}}}{\partial x_{\mathrm{j}}}+\frac{\partial \alpha_{\mathrm{d}} \overline{u_{\mathrm{d}, \mathrm{i}} u_{\mathrm{d}, \mathrm{j}}^{\prime}}}{\partial x_{\mathrm{j}}}=\alpha_{\mathrm{d}} g_{\mathrm{i}}+\alpha_{\mathrm{d}} \frac{3 \mu_{\mathrm{a}}}{\rho_{\mathrm{w}} d^{2}} \frac{C_{\mathrm{d}} \operatorname{Re}_{\mathrm{R}}}{4}\left(\overline{u_{\mathrm{i}}}-\overline{u_{\mathrm{d}, \mathrm{i}}}\right)
\end{aligned}
$$

where $d$ denotes the raindrop diameter, $\alpha_{\mathrm{d}}$ the phase fraction of rain phase $d, u_{\mathrm{d}, \mathrm{j}}$ denotes the velocity component of rain phase $d, u_{\mathrm{i}}$ the velocity component of wind in direction $i, \rho_{\mathrm{w}}$ the density of water, $\mu_{\mathrm{a}}$ is the dynamic viscosity of air, $g_{\mathrm{i}}$ the gravitational acceleration, $C_{\mathrm{d}}$ the drag coefficient. The overbar denotes Reynolds averaging. The terms on the left-hand side are the transient term, the mean convective flux and the turbulent flux. The terms on the right-hand side represent the gravity and the drag forces. Drag coefficients are obtained based on the measurements of terminal velocities of free-falling water droplets by Gunn and Kinzer (1949). $\mathrm{Re}_{\mathrm{R}}$ denotes the relative Reynolds number calculated using the relative velocity between the air and rain phases. Turbulent dispersion of droplets is taken into account by the third term on the left-hand side in Eq. (2). This term is modeled by defining a response coefficient based on the particle relaxation time, which is the rate of response of particle acceleration to the relative velocity between the particle and the carrier fluid, and the Lagrangian fluid time scale, which is the characteristic large eddy lifetime. For a more detailed description of the turbulent dispersion modeling of raindrops, the reader is referred to Kubilay et al. (2015a).

The rain phase calculations are one-way coupled with the air phase, ignoring the effect of raindrops on the wind flow. This is a valid assumption as the volumetric ratio of rain in air is below $1 \times 10^{-3}$ for rainfall intensities up to $20 \mathrm{~mm} / \mathrm{h}$ and below $1 \times 10^{-2}$ for even the most severe cases according to the study by de Wolf (2001). The 
governing equations of rain phases are implemented by the authors into OpenFOAM (2015). The wind-driven rain solver used in the present study can be accessed at the following website:

http://www.carmeliet.ethz.ch/research/downloads/winddrivenrainfoam.html

\subsection{Definitions of the wetting and sheltering parameters}

WDR intensity on a surface is commonly quantified with non-dimensional metrics called specific catch ratio, $\eta_{d}$, and catch ratio, $\eta$, as follows:

$$
\begin{aligned}
& \eta_{\mathrm{d}}(d)=\frac{R_{\mathrm{wdr}}(d)}{R_{\mathrm{h}}(d)}=\frac{\alpha_{\mathrm{d}}\left|V_{\mathrm{n}}(d)\right|}{R_{\mathrm{h}} f_{\mathrm{h}}\left(R_{\mathrm{h}}, d\right)} \\
& \eta=\frac{R_{\mathrm{wdr}}}{R_{\mathrm{h}}}=\int_{d} f_{\mathrm{h}}\left(R_{h}, d\right) \eta_{\mathrm{d}}(d) \mathrm{d} d
\end{aligned}
$$

where the specific catch ratio, $\eta_{d}(d)$, is related to rain phase $d$, while the catch ratio is related to the entire spectrum of raindrop diameters. In Eqs. (3) and (4), $R_{w d r}$ denotes the WDR intensity, $R_{h}$ the horizontal rain intensity through the horizontal plane, $f_{h}\left(R_{h}, d\right)$ the raindrop-size distribution through the horizontal plane and $\left|V_{n}(d)\right|$ the velocity magnitude of the rain phase in the direction normal to the surface. The raindrop-size distribution through a horizontal plane is given in Fig. 2 for different rainfall intensities (Best 1950). For lower rainfall intensities, the probability distribution curve has a sharp shape and raindrops are of smaller size. As the

rainfall intensity increases, larger raindrops tend to get more frequent and the probability distribution curve gets broader.

As the main aim of the present study is to assess the wetting on the passengers, i.e. not on the surfaces, a new metric is defined as the wetting ratio, $\gamma$, which slightly modifies the definition for catch ratio in Eqs. (3) and (4) as follows:

$$
\begin{aligned}
& \gamma_{\mathrm{d}}(d)=\frac{\alpha_{\mathrm{d}}\left\|\mathbf{V}_{d}\right\|}{R_{\mathrm{h}} f_{\mathrm{h}}\left(R_{\mathrm{h}}, d\right)} \\
& \gamma=\int_{d} f_{\mathrm{h}}\left(R_{h}, d\right) \gamma_{\mathrm{d}}(d) \mathrm{d} d
\end{aligned}
$$

by using the magnitude of rain velocity vector, $\mathbf{V}_{d}$. Using the definitions in Eqs. (5) and (6), the wetting in the air for a rainfall intensity $R_{\mathrm{h}}$ is obtained.

Finally, the sheltering efficiency from rain is quantified using the exposure ratio $\delta$, as defined in Eq. (7), which quantifies the exposure to rain by comparing the wetting ratio, $\gamma$, locally at any position around the shelter with the unobstructed wetting ratio, $\gamma_{\infty}$, which is for fully-exposed conditions away from the shelter. Similar metrics 
to the exposure ratio fare also used to quantify sheltering from rain by Hangan (1999), Wu and Kriksic (2012) and Foroushani et al. (2014).

$$
\delta=\frac{\gamma}{\gamma_{\infty}}
$$

\subsection{Computational domain and grid}

For convenience, the same computational domain is used for all wind directions considered in the present study. The dimensions of the computational domain is given in Fig. 3(a). The distances of domain boundaries from the station model satisfy the minimum criteria stated in the CFD best-practice guidelines of Tominaga et al. (2008) and Franke et al. (2011). Maximum blockage ratio of the station shelter is $0.7 \%$, sufficiently smaller than the maximum blockage ratio of $3.0 \%$ suggested in the guidelines.

The computational grid has been generated with snappyHexMesh, which comes with OpenFOAM (2015) and requires the surface geometry of the shelter as input, e.g. in .stl format. The resulting computational grid is composed of mainly hexahedral cells. The computational grid is chosen based on a grid-sensitivity study presented in Allegrini and Kubilay (2017). Three grids are created with the aim to investigate the sensitivity of wind-flow profiles on the cell refinement near walls as well as within the critical waiting area under the shelter roof. The coarse grid consists of 2190574 cells, the medium grid 3353285 cells and the fine grid 4542865 cells. The grid-sensitivity analysis compares the wind velocity along four lines around the shelter for two wind directions: perpendicular to the waiting area (along the $\mathrm{x}$-axis) and an oblique direction ( $45^{\circ}$ with the $\mathrm{x}$-axis). The differences between the medium and fine grids are found to be small for both wind directions, well within the $10 \%$ threshold along all lines. Largest differences in wind speed are observed near the clearance under the back window with a difference of $6.2 \%$ between coarse and medium grids and $5.0 \%$ between medium and fine grids on average. A similar analysis is also carried out in terms of wetting ratio along lines within the waiting area and near the ticket machine for a reference wind speed of $3 \mathrm{~m} / \mathrm{s}$ at a height of $10 \mathrm{~m}$ and a reference rainfall intensity of $1 \mathrm{~mm} / \mathrm{h}$. Between the coarse and medium grids, a difference of $12.8 \%$ is observed within the waiting area and a difference of $0.7 \%$ near the ticket machine on average. Refining the mesh further resulted in a difference of $7.7 \%$ within the waiting area and $0.8 \%$ near the ticket machine. Due to small differences in peak values at critical positions, the fine grid is chosen for the rest of the study. The computational grid on the surface of the shelter and part of the ground and cross-sections in xy and xz-planes are given in Fig. 3(b)-(d). The smallest cell height is about $3 \mathrm{~mm}$ on the structure surfaces in order to capture the surface shape well and 200 $\mathrm{mm}$ on the ground. The average $\mathrm{y}+$ is found to be 1800 on the ground surface and 17 on the structure surfaces.

\subsection{Boundary conditions}

\subsubsection{Boundary conditions for wind flow}


The inlet profile of the mean wind speed is given by the typical log-law expression as described in Eq. (8). The inlet profiles of the turbulence kinetic energy $k$ and turbulence dissipation rate $\varepsilon$ are defined by Eqs. (9) and (10) following the definitions by Richards and Hoxey (1993). In Eqs. (8-10), $U(y)$ denotes the mean streamwise wind speed at a height $y$ above the ground plane, $u^{*}{ }_{\mathrm{ABL}}$ the atmospheric boundary layer (ABL) friction velocity, $\kappa$ the von Karman constant ( 0.42 in the present study), $y_{0}$ the aerodynamic roughness length and $C_{\mu}$ a model constant. The aerodynamic roughness length $y_{0}$ is taken as $0.1 \mathrm{~m}$, representing moderately open natural area with occasional obstacles (Wieringa 1992).

$$
\begin{aligned}
& U(y)=\frac{u_{\mathrm{ABL}}^{*}}{\kappa} \ln \left(\frac{y+y_{0}}{y_{0}}\right) \\
& k(y)=\frac{u_{\mathrm{ABL}}^{*}{ }^{2}}{C_{\mu}^{0.5}} \\
& \varepsilon(y)=\frac{u_{\mathrm{ABL}}^{*}{ }^{3}}{\kappa\left(y+y_{0}\right)}
\end{aligned}
$$

Note that, for oblique wind directions, identical inlet conditions are set for the two domain boundaries from where the wind approaches the shelter. The remaining two vertical boundaries of the computational domain are defined with outlet conditions. At the outlet boundary, a constant static gauge pressure of $0 \mathrm{~Pa}$ is set.

For wall treatment, the standard wall functions by Launder and Spalding (1974) with sand-grain roughness modification (Cebeci and Bradshaw 1977) are used. In order to limit the unintended horizontal inhomogeneity, the equivalent sand-grain roughness height, $k_{\mathrm{s}}$, and the roughness constant, $C_{\mathrm{s}}$, are determined using the following relation (Blocken et al. 2007b):

$$
k_{\mathrm{s}}=\frac{E y_{0}}{C_{\mathrm{s}}}
$$

where $E$ is an empirical constant with a value of 9.793. For the ground surface of the computational domain, $k_{\mathrm{s}}$ is taken to be $0.1 \mathrm{~m}$ and $C_{\mathrm{s}}$ is set as 9.793 , leading to an aerodynamic roughness length $y_{0}=0.1 \mathrm{~m}$. This way, the $\mathrm{ABL}$ mean velocity profile at the inlet matches the parameters of the wall functions with roughness modification. The shelter surfaces are assumed to be smooth $\left(k_{\mathrm{s}}=0\right)$.

For the top boundary, constant values are set for $U, k$ and $\varepsilon$ by using fixed values from the inlet profiles at the same height as suggested by Blocken et al. (2007b), in order to further limit the horizontal inhomogeneity, as other top boundary conditions, such as symmetry condition, can cause streamwise gradients.

\subsubsection{Boundary conditions for wind-driven rain}


For the rain phases, inlet boundaries are defined as the boundaries from which rain enters the computational domain, i.e. the inlet boundaries for the wind phase as defined in section 3.4.1 and the top boundary. For these boundaries, the values of rain-phase velocity, $u_{\mathrm{d}, \mathrm{j}}$, and rain-phase fraction, $\alpha_{\mathrm{d}}$, are defined for each rain phase $d$.

The vertical inlet rain phase velocity component is set equal to the terminal velocity for that phase. The terminal velocities are obtained from the measured data of Gunn and Kinzer (1949). The horizontal component of rainphase velocity for each different raindrop size will be different as they have different inertia and drag force. Therefore, the horizontal component of rain-phase velocity should have a local force equilibrium between the rain and wind phases so that the droplets neither accelerate nor decelerate in an unobstructed computational domain. This is achieved as follows: A recycling plane is defined, located $5 \mathrm{~m}$ downstream of the inlet plane. The raindrop velocity profile at the recycling plane is imposed back at the inlet plane. The inlet/recycling plane couple can also be defined as a "pseudo-periodic condition" at the upstream of the computational domain. This way, the inflow profile for raindrops are generated by itself, which represents a fully-developed rain velocity profile distinct for each separate rain phase.

The phase fraction for rain phase $d$ at the inlet can be calculated using:

$$
\alpha_{\mathrm{d}}=\frac{R_{\mathrm{h}} f_{\mathrm{h}}\left(R_{\mathrm{h}}, d\right)}{V_{\mathrm{t}}(d)}
$$

where $V_{\mathrm{t}}(d)$ represents the terminal velocity of a raindrop with diameter $d$ and $f_{\mathrm{h}}\left(R_{\mathrm{h}}, d\right)$ the raindrop-size distribution through the horizontal plane (Best 1950).

The boundary conditions at the building walls, on the ground and at the outlet are set in such way that the normal gradient of the phase fraction, $\partial \alpha_{d} / \partial n$, equals zero when the normal wind velocity vector is pointing out of the domain, and the values of the phase fraction, $\alpha_{\mathrm{d}}$, are equal to zero when the normal wind velocity vector is pointing into the domain. With these boundary conditions, the interaction between the raindrops and the walls are not modeled and the raindrops leave the domain as soon as they hit a wall boundary. Current study does not consider splashing on the surfaces or water dripping from the structure itself.

\subsection{Validation of the WDR model}

The numerical model presented in this section is validated using data from field measurements on several geometries during several rain events with different characteristics. The validation studies include comparisons of numerical and experimental WDR intensity on a tower building in the Netherlands (Briggen et al. 2009; Kubilay et al. 2013; Kubilay et al. 2015b) and on model cubes of $2 \mathrm{~m}$ that are arranged in a regular array (Kubilay et al. 2014) and as two buildings with different heights (Kubilay et al. 2015b) in Switzerland as shown in Fig. 4(a). 
Fig. 4(b) shows, as an example, the comparison of cumulative WDR during one of the selected rain events measured on September 16-19, 2013 on the array of cubes (Kubilay et al. 2014). For the field measurements, a total of 18 WDR gauges are positioned on two cubes. The gauges are composed of collectors located outside and tipping bucket sensors located inside the cubes. For the validation study, 10-min averaged wind speed and wind direction as well as 10-min summed horizontal rainfall amount are used as boundary conditions. The comparison on the downstream cube, marked in gray in Fig. 4(b), shows that the numerical estimations follow the experimental data very accurately except for a short duration at the end, with spikes of short rain spells, which causes larger discrepancy for some locations on the facade. The average discrepancy is found to be $6.5 \%$ for the upstream cube and $12.0 \%$ for the downstream cube. In general, the validation studies show that the EM model can successfully predict the response of different-size raindrops to the wind-flow field, given the fact that the parameters such as wind direction, wind speed and rainfall intensity may vary considerably during a rain event.

\section{Simulation settings}

\subsection{Meteorological data}

For the rain sheltering analysis, two locations in Switzerland are chosen: Zurich and La Chaux-de-Fonds. Both measurement stations are located at the airports in the respective locations outside of the city centers. Surroundings of the measurement stations can be described as roughly open natural areas with low crops and isolated obstacles, as prescribed in the boundary conditions in section 3.4.1. The measured data are assumed to represent the rural regions in the vicinity. Fig. 5 presents the yearly meteorological conditions during rain for the two locations based on a typical meteorological year (Meteonorm 2000). A typical meteorological year represents a collection of standardized data obtained from long-term mean values. The wind roses during rain for both locations show a clear distinction. The wind rose for Zurich shows a more uniform distribution of wind directions during rain with westerly wind being slightly more predominant. The wind rose for La Chaux-deFonds indicates clearly higher probabilities for wind directions along northwest and southeast. This difference allows for estimating the sensitivity of yearly rain exposure results on predominant wind directions.

In fact, apart from the differences in wind direction, the data from the two locations are similar in terms of average wind speed and rainfall intensity. The distribution of meteorological conditions based on the histogram for Zurich indicates that the wind speed at $10 \mathrm{~m}$ height is $40.4 \%$ of the time higher than $3 \mathrm{~m} / \mathrm{s}$ and $15.7 \%$ of the time higher than $5 \mathrm{~m} / \mathrm{s}$ during rainy hours. The annual rainfall amount is $1121 \mathrm{~mm}$. The average wind speed during rain is $3.0 \mathrm{~m} / \mathrm{s}$ and the average rainfall intensity is $1.1 \mathrm{~mm} / \mathrm{h}$. For La Chaux-de-Fonds, during rainy hours, the wind speed at $10 \mathrm{~m}$ height is $48.0 \%$ of the time higher than $3 \mathrm{~m} / \mathrm{s}$ and $12.8 \%$ of the time higher than $5 \mathrm{~m} / \mathrm{s}$. The annual rainfall amount is $1448 \mathrm{~mm}$. The average wind speed during rain is $3.3 \mathrm{~m} / \mathrm{s}$ and the average rainfall intensity is $1.1 \mathrm{~mm} / \mathrm{h}$.

\subsection{Solution strategy}


The range of the meteorological conditions considered during WDR simulations is chosen based on the data obtained from Fig. 5. First, the wind-flow field around the shelter is solved for a reference wind speed of $U_{10}=3$ $\mathrm{m} / \mathrm{s}$ for 12 different wind directions with an increment of $30^{\circ}$, where $U_{10}$ denotes the mean wind speed at $\mathrm{y}=10$ $\mathrm{m}$ height from the ground. The wind-flow fields for other values of the reference wind speed $\left(U_{10}=1,5,10\right.$ and $15 \mathrm{~m} / \mathrm{s}$ ) are obtained by linear scaling. For the scaled wind speed values, the corresponding fields for turbulent viscosity, turbulence kinetic energy, turbulence dissipation rate are obtained by linear, quadratic and cubic scaling, respectively. Second, the governing equations for the rain phases are solved as separate simulations for each wind speed and wind direction. Specific catch ratio distributions are calculated for several raindrop diameters (17 diameters ranging from 0.3 to $1 \mathrm{~mm}$ in steps of $0.1 \mathrm{~mm}$, from 1 to $2 \mathrm{~mm}$ in steps of $0.2 \mathrm{~mm}$ and from 2 to $6 \mathrm{~mm}$ in steps of $1 \mathrm{~mm}$ ). Catch ratio and wetting ratio distributions are obtained for 6 reference horizontal rainfall intensities of $R_{h}=0,0.1,1,5,10,30 \mathrm{~mm} / \mathrm{h}$ based on the droplet-size distribution by Best (1950).

The pressure-velocity coupling for the wind-flow field solution is taken care of with the Semi-Implicit Method for Pressure Linked Equations (SIMPLE) algorithm. Second-order discretization schemes are used for both the convection terms and the viscous terms of the governing equations. For both the air and rain phase calculations, the simulations are terminated when all the scaled residuals reach $10^{-6}$. A single calculation of wind-flow field took about 8 hours to converge (12 simulations in total), whereas a single calculation of WDR took about 5 hours (60 simulations in total) on parallel runs with 24 processors.

\section{Results}

\subsection{Flow patterns of wind and rain}

The local wind-flow patterns formed around the station shelter can highly influence the provided sheltering from rain. Given certain aspects of the studied shelter prototype, such as the different roof lengths on each side of the support structure or the absence of a back window on one side of the shelter, distinct sheltering properties are obtained for different wind directions. Fig. 6 shows the wind-flow patterns around the station shelter on a vertical plane passing through the center of the waiting area for $\varphi=0^{\circ}$ and $180^{\circ}$ and on the vertical centerplane for $\varphi=90^{\circ}$ and $270^{\circ}$. For the wind direction $\varphi=0^{\circ}$, a stagnation point is observed on the back window. The resulting wind-flow field indicates an accelerated flow directed into the waiting area through the clearance under the back window. Apart from this, a low velocity clockwise recirculation is observed within the waiting area. For $\varphi=90^{\circ}$, the wind speed within the waiting area is relatively higher, while the region with the ticket machine is protected from the wind. For $\varphi=180^{\circ}$, a standing vortex is visible located upwind of the waiting area. The approaching wind is further directed downwards under the roof and through the clearance. For $\varphi=270^{\circ}$, the high velocity region reaches up to the ticket machine, whereas the waiting area is shielded by the support structure.

The influence of the wind-flow patterns shown in Fig. 6 is different for each raindrop size. Considering the given raindrop-size distribution in Fig. 2 and the meteorological data in Fig. 5, trajectories for the raindrop sizes $d=$ 
$0.3,1.0$ and $2.0 \mathrm{~mm}$ at $U_{10}=3 \mathrm{~m} / \mathrm{s}$ are presented in Fig. 7. The raindrop size $d=0.3 \mathrm{~mm}$ indicates the lower end of the spectrum, which represents drizzle. The raindrop sizes $d=1.0$ and $2.0 \mathrm{~mm}$ cover a significant proportion of all the raindrops in the air for a large range of rainfall intensities. For the wind direction $\varphi=0^{\circ}$ in Fig. 7(a), the waiting area is sheltered from rain by the back window for all raindrop sizes. On the other side, raindrops can reach the area with the ticket machine. The $0.3-\mathrm{mm}$ raindrops can travel through the whole width of the shelter due to their low inertia. In comparison, the $1.0-\mathrm{mm}$ raindrops can reach until about the middle of the area with the ticket machine. The area is mostly sheltered from $2.0-\mathrm{mm}$ raindrops. For $\varphi=90^{\circ}$, the smallest raindrops can reach quite far under the roof, whereas the larger raindrops can wet around $1 / 4^{\text {th }}$ of the waiting area. For $\varphi=$ $180^{\circ}, 0.3-\mathrm{mm}$ raindrops are influenced by the standing vortex seen in Fig. 6(c). Raindrops of 1.0 and $2.0 \mathrm{~mm}$, on the other hand, are less influenced by the local flow patterns and can reach the seats. For the area with the ticket machine, the raindrops can reach slightly further compared to the wind direction $\varphi=0^{\circ}$. The reason for this is that, for $\varphi=0^{\circ}$, the corner stream around the back window slows down the raindrops, which is not the case for $\varphi=180^{\circ}$. For $\varphi=270^{\circ}$, the smaller raindrops can reach under the roof up to the ticket machine, whereas the 2.0$\mathrm{mm}$ raindrops can reach halfway. The waiting area is sheltered for all three raindrop sizes.

Raindrop trajectories give an insight into rain sheltering. However, they can also be misleading as they provide no information about the existing amount of each raindrop size present in the air. The catch ratio can be used to compare the surface wetting based on the probability distribution of the complete spectrum of raindrop sizes for a reference rainfall intensity. Fig. 8 compares the catch ratio for a rainfall intensity of $1 \mathrm{~mm} / \mathrm{h}$ for 4 main wind directions. The waiting area is exposed the most for the wind direction $\varphi=180^{\circ}$ and is partially exposed for $\varphi=90^{\circ}$. As also seen in Fig. 7(c) for $\varphi=180^{\circ}$, the seat surfaces are exposed to rain with a catch ratio of more than 0.3 . The high catch ratio regions on the ground $(\eta \approx 1.2)$ are observed except for $\varphi=180^{\circ}$ due to the standing vortex and strong downward flow upstream of the back window $\left(\varphi=0^{\circ}\right)$ and corner flows around the back window $\left(\varphi=90^{\circ}\right.$ and $\left.270^{\circ}\right)$.

\subsection{Analysis of rain sheltering}

The exposure ratios, $\delta$, in vertical planes for 4 main wind directions are presented in Fig. 9 for a rainfall intensity of $1 \mathrm{~mm} / \mathrm{h}$. Fig. 9 indicates the regions that are fully exposed, fully sheltered, and partially sheltered around the station shelter. While the catch ratio values on the surfaces in Fig. 8 can be used to compare sheltering performance, a volumetric analysis for the exposure of passengers is more meaningful. The partial exposure regions indicated in Fig. 9, i.e. $\delta$ values between 0 and 1, are due to the fact that these regions are sheltered from some raindrop sizes and not from others. This provides interesting information because it takes into account the probability density of raindrop size as opposed to raindrop trajectories. For example, the furthest positions the raindrop sizes $d=0.3$ and $1.0 \mathrm{~mm}$ reach within the waiting area are marked in Fig. 9(b). The position for the smallest raindrops indicates an exposure ratio smaller than 0.05 because the probability of 0.3 -mm raindrops is low for a rainfall intensity of $1 \mathrm{~mm} / \mathrm{h}$. Note that the distribution of exposure ratio $\delta$ will differ at a different rainfall intensity or wind speed. Therefore, in the following part, the analyses are made for the exposure of several positions that indicate the positions of passengers along for various meteorological conditions. Fig. 10 shows the lines for the 5 positions included in the analyses. The exposure ratios are compared along these lines 
between the heights $\mathrm{y}=0$ and $1.75 \mathrm{~m}$. Position 1 corresponds to a passenger by the ticket machine, while the remaining positions are within the waiting area.

Fig. 11 compares the exposure ratio at the 5 passenger positions for a total of 12 wind directions, with an increment of $30^{\circ}$, for 3 wind speeds $(1,3$ and $5 \mathrm{~m} / \mathrm{s}$ at $10 \mathrm{~m}$ height) and 3 rainfall intensities $(0.1,1$ and $5 \mathrm{~mm} / \mathrm{h})$. The values for exposure ratio are averaged along the lines shown in Fig. 10. There is a general trend for all positions that the exposure ratio increases as expected with wind speed. Similarly, the exposure to rain increases monotonically from position 2 to 5 within the waiting area. However, there does not seem to be a general trend for a change in rainfall intensity. In some cases, an increase in rainfall intensity results in more raindrops focused at a specific position. For example, for $\varphi=0^{\circ}$, as wind speed increases, even larger raindrops are directed towards position 1 due to the corner flow around the back window, which results in a higher exposure to rain. In general, the shelter provides the highest protection from rain for wind direction $\varphi=30^{\circ}$ for all positions. As the wind direction changes towards $\varphi=180^{\circ}$, the exposure to rain increases within the waiting area. The shelter is most exposed to rain for all positions for $\varphi=180^{\circ}$. For $\varphi=270^{\circ}-360^{\circ}$, the waiting area is almost completely sheltered from rain, whereas position 1 near the ticket machine is exposed to rain for wind speeds higher than 3 $\mathrm{m} / \mathrm{s}$.

\subsection{Analysis based on yearly rain data}

Using the exposure ratios calculated for a range of reference conditions, the most and least effective orientations in terms of rain sheltering can be obtained based on yearly meteorological data. Fig. 12 shows the yearly exposure ratio, $\delta_{\mathrm{a}}$, for each position, which is calculated by interpolating the exposure ratio $\delta$ for the reference conditions based on rain data from the typical meteorological year. $\delta_{\mathrm{a}}$ values are weighted with the rainfall intensity $\mathrm{R}_{\mathrm{h}}$ as follows:

$$
\delta_{a}=\frac{\delta(n) R_{h}(n)}{\sum_{n} R_{h}(n)}
$$

where $n$ denotes the hourly timestep within the meteorological year.

In Fig. 12, the orientation angle $\beta$ denotes the angle between the normal to the back window and the north (see the small sketch in Fig. 12), e.g. $\beta=90^{\circ}$ corresponds to the most sheltered conditions for the waiting area for wind from west. The general trend of exposure ratio with respect to the orientation angle is similar for Zurich and La Chaux-de-Fonds. However, the maximum values are higher and the minimum values are lower in La Chaux-de-Fonds due to the less uniform nature of wind direction during rain. For position 1 near the ticket machine, the exposure ratio does not change significantly with the orientation of the shelter, the values being between 0.21 and 0.26 in Zurich and between 0.19 and 0.26 in La Chaux-de-Fonds. The lowest exposure ratios are observed for $\beta=150^{\circ}$ and $180^{\circ}$, which is due to partial sheltering by the support structure. Within the waiting area, the yearly exposure ratios increase from position 2 to 5 , as expected based on the results presented 
in Fig. 11. For all positions within the waiting area, exposure ratios increase towards $\beta=240^{\circ}$, which exposes the waiting area for winds from west-northwest. Furthermore, for these wind directions, the acceleration of wind flow around the side window results in an increased exposure ratio. The highest yearly exposure ratio for position 5 is 0.37 for Zurich and 0.40 for La Chaux-de-Fonds. Overall, the largest differences between the exposure ratios in Zurich and La Chaux-de-Fonds are 23.0\%, 30.2\%, 25.0\%, 19.6\% and 18.9\% for positions 1 through 5, respectively.

\subsection{Influence of geometrical modifications in the waiting area}

Based on the results obtained in the previous sections, the impacts of two relatively simple geometrical modifications on the rain exposure of the waiting area are assessed. The two geometrical modifications are shown in Fig. 13. The first modification aims to decrease the rain exposure ratio within the waiting area by the use of a wider side window. As shown in Fig. 13(a), the extended side window is as wide as the shelter roof $(1.5 \mathrm{~m}$ instead of $0.75 \mathrm{~m})$. The second modification focuses on the effect of the clearance between the ground and the back window. Fig. 6(c) indicates wind flow through the clearance when the predominant wind direction is from the front $\left(\varphi=180^{\circ}\right)$. Here, the impact of this accelerated wind flow on the rain exposure is estimated by closing the clearance completely along the back window as shown in Fig. 13(b).

The impact of the wider side window is analyzed only for the wind directions where it can block the approach wind flow, e.g. wind directions $\varphi=60^{\circ}, 90^{\circ}, 120^{\circ}$ and $150^{\circ}$. Fig. 14 compares the exposure ratios after the modification with the ones for the original geometry. The bar graphs with thick black outline show the exposure ratio after the modification, while the ones with thin red outline show the values before. The extended side

window provides a clear protection from rain and lowers the exposure ratio completely for all positions for wind directions $\varphi=60^{\circ}$ and $90^{\circ}$. If the wind direction is more oblique and directed towards the waiting area, the protection by the side window decreases. For $\varphi=120^{\circ}$, the decrease in exposure ratio is up to $95 \%$ for position 5 , up to $60 \%$ for position 4 and up to $22 \%$ for position 3 . The impact of the side window increases as rainfall intensity decreases and as wind speed increases. At lower rainfall intensities, there are more of the smaller raindrops in the air, which have lower inertia and can be influenced more by the local wind-flow patterns. Similarly, at higher wind speeds, increasingly larger raindrops can be influenced by the local wind-flow patterns, which results in a higher impact by the extended side window. Note that, rain exposure at position 2 increases if an extended side window is used. For $\varphi=150^{\circ}$, the impact of the extended side window is limited. The only significant decrease in exposure ratios is for position 5 by up to $16 \%$. The results in Fig. 14 show that, for certain conditions, the extended side window can provide significantly more sheltering, especially for orientations which would lead to high probability of rain from wind directions $\varphi=90^{\circ}$ and $120^{\circ}$.

The exposure ratios after closing the clearance under the back window are compared with the ones for the original geometry in Fig. 15 for the wind direction $\varphi=180^{\circ}$. Indeed, as a result of the modification, the wind flow through the clearance is hindered and the rain exposure decreases. However, this impact is valid only for very small raindrops and, therefore, the decrease is quite limited, with the highest decrease being $4.9 \%$. Considering that the decrease mainly occurs at very low rainfall intensities, e.g. $0.1 \mathrm{~mm} / \mathrm{h}$, it can be stated that 
the clearance has no impact on the rain exposure within the waiting area. Note that the increased wind speed through the clearance can also have an impact on wind comfort and can increase wind-chill effect in winter (discussed in Allegrini and Kubilay (2017)). However, these influences are outside of the scope of the present study.

\section{Discussion}

This paper studies the wind-driven rain exposure of a railway station shelter. Note that the shelter prototype in the present study is not meant to provide complete shelter for extreme weather conditions. For such extreme weather conditions, a totally-closed shelter would be needed. For the analyses in sections 5.2, 5.3 and 5.4, the exposure ratios are averaged along the lines shown in Fig. 10, which represent the total height of a standing passenger. This approach assumes that wetting due to rain leads to equal level of discomfort whether it is the leg or the head that is exposed. The exposure ratios would mostly decrease in case only the upper torso and the head of passengers are considered.

The present study employs several geometrical simplifications. First, the numerical simulations consider a standalone railway shelter without any nearby buildings or vegetation. Considering the fact that the shelter prototype is designed for rural areas, it can be assumed that the nearby area will not have dense urban regions and the station is not sheltered by surrounding buildings. On the other hand, in real situations, nearby similar size buildings or vegetation may alter the wind flow and have an influence on rain exposure, especially at lowmedium rainfall intensities. Nearby objects, depending on their size and position, can decrease the WDR exposure by blocking the wind flow or further increase it by accelerating the wind flow. Second, the surrounding terrain is assumed to be flat, where, in reality, this does not have to be the case. Numerical simulations of winddriven rain on uneven terrain show that the upwind slope of a hill and the downwind slope of a valley receive more rainfall as a result of the observed wind-flow patterns (Blocken et al. 2006). Therefore, placement of the railway shelter on uneven terrain will change the rain exposure of passengers. Third, train tracks, and possible step change in surface due to the tracks, are not considered. The omission of the train tracks can influence the wetting of passengers, especially for wind direction $\varphi=180^{\circ}$. The impact of such geometrical simplifications should be analyzed in detail in numerical studies on a particular case study in a specific location. The present study focuses on the influence of the presence of the station shelter on its own rain exposure.

The present study does not model water film runoff on the shelter surfaces. Such an analysis would give information related to the water dripping from the edges of the roof and the removal of excess water. Note also that the droplet physics after impact, e.g. splashing, bouncing, are neglected. Accurate modeling of droplet behavior after impact would require taking into account parameters such as surface roughness and porosity in addition to droplet impact velocity. However, this study assumes that splashing/bouncing droplets would only lead to a minor influence on the rain exposure of passengers waiting within the shelter area for most cases. Therefore, the predicted values for passenger rain exposure only indicate the amount before the raindrops come in contact with the surfaces. 


\section{Conclusion}

Numerical simulations of wind-driven rain are performed for a stand-alone railway station shelter for various meteorological conditions. The simulations of wind-driven rain are based on an Eulerian multiphase approach, which allows for an analysis of wetting amount within a volume in the air, as well as on the surfaces for any combination of wind speed, wind direction and rainfall intensity.

This study introduces a new metric called wetting ratio. Wetting ratio considers the raindrop velocity in the air and allows for a complete analysis within a volume of air in addition to the common approach for surface wetting. This metric is applied on a case study focusing on a railway station shelter. Specifically, rain exposure of passengers within the shelter is compared to fully-exposed conditions. The analyses indicate the most sheltered and most exposed locations under the shelter roof referring to positions of standing passengers for different meteorological conditions. Yearly analyses are performed using typical meteorological year data from two locations in Switzerland for different orientations of the shelter. The results show limited sheltering near the ticket machine, where there is no back window. The back window, which is situated in the waiting area, offers significant protection from rain. However, towards the side edge of the waiting area, rain exposure increases significantly. It has been found that the yearly rain exposure differs based on the local meteorological conditions, e.g. for La Chaux-de-Fonds, which experiences more pronounced wind directions during rain, the maximum rain exposure ratios increase and the minimum values decrease compared to Zurich.

It should be noted that some conclusions obtained in the present study are case specific and cannot be generalized to impose general design criteria. On the other hand, the study shows that minor geometrical modifications, e.g. side windows, can influence the WDR exposure significantly for certain conditions. Similar minor modifications can be an option based on the local meteorological conditions and the orientation of the shelter, as such shelters are usually produced in large numbers. Removal of such features might decrease the effectiveness of whole shelter. Furthermore, the geometry of the shelter has common features for tram and bus stations, for which the results can be extended further.

\section{Acknowledgments}

This project was conducted in collaboration with Swiss Federal Railways (SBB). The shelter prototype was designed by SBB and they have the intellectual property of the design. Funding by Swiss Federal Railways (SBB) is gratefully acknowledged. 


\section{References}

Abuku, M., Blocken, B., and Roels, S. 2009a. Moisture response of building facades to wind-driven rain: Field measurements compared with numerical simulations. J. Wind Eng. Ind. Aerodyn. 97 (5-6):197-207.

Abuku, M., Blocken, B., Nore, K., Thue, J.V., Carmeliet, J., and Roels, S. 2009b. On the validity of numerical wind-driven rain simulation on a rectangular low-rise building under various oblique winds. Build Environ 44 (3):621-632.

Allegrini, J., and Kubilay, A. 2017. Wind sheltering effect of a small railway station shelter and its impact on wind comfort for passengers. J. Wind Eng. Ind. Aerodyn. 164:82-95.

Best, A.C. 1950. The size distribution of raindrops. Q J Roy Meteor Soc 76 (327):16-36.

Blocken, B., and Carmeliet, J. 2002. Spatial and temporal distribution of driving rain on a low-rise building. Wind Struct 5 (5):441-462.

Blocken, B., and Carmeliet, J. 2006. The influence of the wind-blocking effect by a building on its wind-driven rain exposure. $J$ Wind Eng Ind Aerod 94 (2):101-127.

Blocken, B., and Carmeliet, J. 2007. Validation of CFD simulations of wind-driven rain on a low-rise building facade. Build Environ 42 (7):2530-2548.

Blocken, B., Dezso, G., van Beeck, J., and Carmeliet, J. 2009. The mutual influence of two buildings on their wind-driven rain exposure and comments on the obstruction factor. J Wind Eng Ind Aerod 97 (5-6):180-196.

Blocken, B., Poesen, J., and Carmeliet, J. 2006. Impact of wind on the spatial distribution of rain over micro-scale topography: numerical modelling and experimental verification. Hydrological processes 20 (2):345-368.

Blocken, B., Roels, S., and Carmeliet, J. 2007a. A combined CFD-HAM approach for wind-driven rain on building facades. $J$ Wind Eng Ind Aerod 95 (7):585-607.

Blocken, B., Stathopoulos, T., and Carmeliet, J. 2007b. CFD simulation of the atmospheric boundary layer: wall function problems. Atmos Environ 41 (2):238-252.

Briggen, P.M., Blocken, B., and Schellen, H.L. 2009. Wind-driven rain on the facade of a monumental tower: numerical simulation, fullscale validation and sensitivity analysis. Build Environ 44 (8):1675-1690.

Cebeci, T., and Bradshaw, P. 1977. Momentum transfer in boundary layers. New York: Hemisphere Publishing Corporation.

Choi, E.C.C. 1991. Numerical simulation of wind-driven rain falling onto a 2-D building. Asia Pacific Conf. on Computational Mechanics, Hong Kong.

Choi, E.C.C. 1994. Determination of wind-driven-rain intensity on building faces. J Wind Eng Ind Aerod 51 (1):55-69.

de Wolf, D.A. 2001. On the Laws-Parsons distribution of raindrop sizes. Radio Sci 36 (4):639-642.

Etyemezian, V., Davidson, C.I., Zufall, M., Dai, W., Finger, S., and Striegel, M. 2000. Impingement of rain drops on a tall building. Atmos Environ 34:2399-2412.

Fiala, D., Havenith, G., Bröde, P., Kampmann, B., and Jendritzky, G. 2012. UTCI-Fiala multi-node model of human heat transfer and temperature regulation. International Journal of Biometeorology 56 (3):429-441.

Foroushani, M.S.S., Ge, H., and Naylor, D. 2014. Effects of roof overhangs on wind-driven rain wetting of a low-rise cubic building: A numerical study. $J$ Wind Eng Ind Aerod 125 (0):38-51.

Franke, J., Hellsten, A., Schlunzen, K.H., and Carissimo, B. 2011. The COST 732 Best practice guideline for CFD simulation of flows in the urban environment: a summary. Int J Environ Pollut 44 (1-4):419-427.

Ge, H., Deb Nath, U.K., and Chiu, V. 2017. Effect of overhang on wind-driven rain wetting of facades on a mid-rise building: Field measurements. Build Environ 118:234-250.

Gunn, R., and Kinzer, G.D. 1949. The terminal velocity of fall for water droplets in stagnant air. J Meteorol 6 (4):243-248.

Hangan, H. 1999. Wind-driven rain studies. A C-FD-E approach. J Wind Eng Ind Aerod 81:323-331.

van Hooff, T., Blocken, B., and van Harten, M. 2011. 3D CFD simulations of wind flow and wind-driven rain shelter in sports stadia: Influence of stadium geometry. Build Environ 46 (1):22-37.

Huang, S.H., and Li, Q.S. 2010. Numerical simulations of wind-driven rain on building envelopes based on Eulerian multiphase model. $J$ Wind Eng Ind Aerod 98 (12):843-857.

Kubilay, A. 2014. Numerical simulations and field experiments of wetting of building facades due to wind-driven rain in urban areas. Ph.D. thesis, ETH Zurich, Switzerland.

Kubilay, A., Carmeliet, J., and Derome, D. 2017. Computational fluid dynamics simulations of wind-driven rain on a mid-rise residential building with various types of facade details. Journal of Building Performance Simulation 10 (2):125-143.

Kubilay, A., Derome, D., Blocken, B., and Carmeliet, J. 2013. CFD simulation and validation of wind-driven rain on a building facade with an Eulerian multiphase model. Build Environ 61:69-81.

Kubilay, A., Derome, D., Blocken, B., and Carmeliet, J. 2014. Numerical simulations of wind-driven rain on an array of low-rise cubic buildings and validation by field measurements. Build Environ 81 (0):283-295.

Kubilay, A., Derome, D., Blocken, B., and Carmeliet, J. 2015a. Numerical modeling of turbulent dispersion for wind-driven rain on building facades. Environ Fluid Mech 15 (1):109-133.

Kubilay, A., Derome, D., Blocken, B., and Carmeliet, J. 2015b. Wind-driven rain on two parallel wide buildings: field measurements and CFD simulations. $J$ Wind Eng Ind Aerod 146:11-28.

Launder, B.E., and Spalding, D.B. 1974. The numerical computation of turbulent flows. Comput. Methods Appl. Mech. Eng. 3:269-289.

Meteonorm. 2000. Global meteorological database for solar energy and applied climatology. Bern, Switzerland, Meteotest.

van Mook, F.J.R. 2002. Driving rain on building envelopes. In.: Ph.D. thesis, Eindhoven University of Technology, Eindhoven, The Netherlands.

NEN 8100. 2006. Wind comfort and wind danger in the built environment (In Dutch). NEN Dutch standard, Netherlands.

OpenFOAM. 2015. OpenCFD Ltd. OpenFOAM v2.4.0 User guide. Retrieved from http://www.openfoam.com 
Persoon, J., van Hooff, T., Blocken, B., Carmeliet, J., and de Wit, M.H. 2008. On the impact of roof geometry on rain shelter in football stadia. J. Wind Eng. Ind. Aerodyn. 96 (8-9):1274-1293.

Richards, P.J., and Hoxey, R.P. 1993. Appropriate boundary conditions for computational wind engineering models using the k- $\epsilon$ turbulence model. J Wind Eng Ind Aerod 46-47 (0):145-153.

Shih, T.-H., Liou, W.W., Shabbir, A., Yang, Z., and Zhu, J. 1995. A new k-€ eddy viscosity model for high reynolds number turbulent flows. Comput Fluids 24 (3):227-238.

Shirolkar, J.S., Coimbra, C.F.M., and McQuay, M.Q. 1996. Fundamental aspects of modeling turbulent particle dispersion in dilute flows. Progress in Energy and Combustion Science 22 (4):363-399.

Tang, W., and Davidson, C.I. 2004. Erosion of limestone building surfaces caused by wind-driven rain: 2. numerical modeling. Atmos Environ 38 (33):5601-5609.

Tominaga, Y., Mochida, A., Yoshie, R., Kataoka, H., Nozu, T., Yoshikawa, M., and Shirasawa, T. 2008. AIJ guidelines for practical applications of CFD to pedestrian wind environment around buildings. J Wind Eng Ind Aerod 96 (10-11):1749-1761.

Wang, H., Hou, X., and Deng, Y. 2015. Numerical simulations of wind-driven rain on building facades under various oblique winds based on Eulerian multiphase model. J. Wind Eng. Ind. Aerodyn. 142:82-92.

Wieringa, J. 1992. Updating the Davenport roughness classification. J Wind Eng Ind Aerod 41 (1-3):357-368.

Wu, H., and Kriksic, F. 2012. Designing for pedestrian comfort in response to local climate. J. Wind Eng. Ind. Aerodyn. 104-106:397407. 
Figures
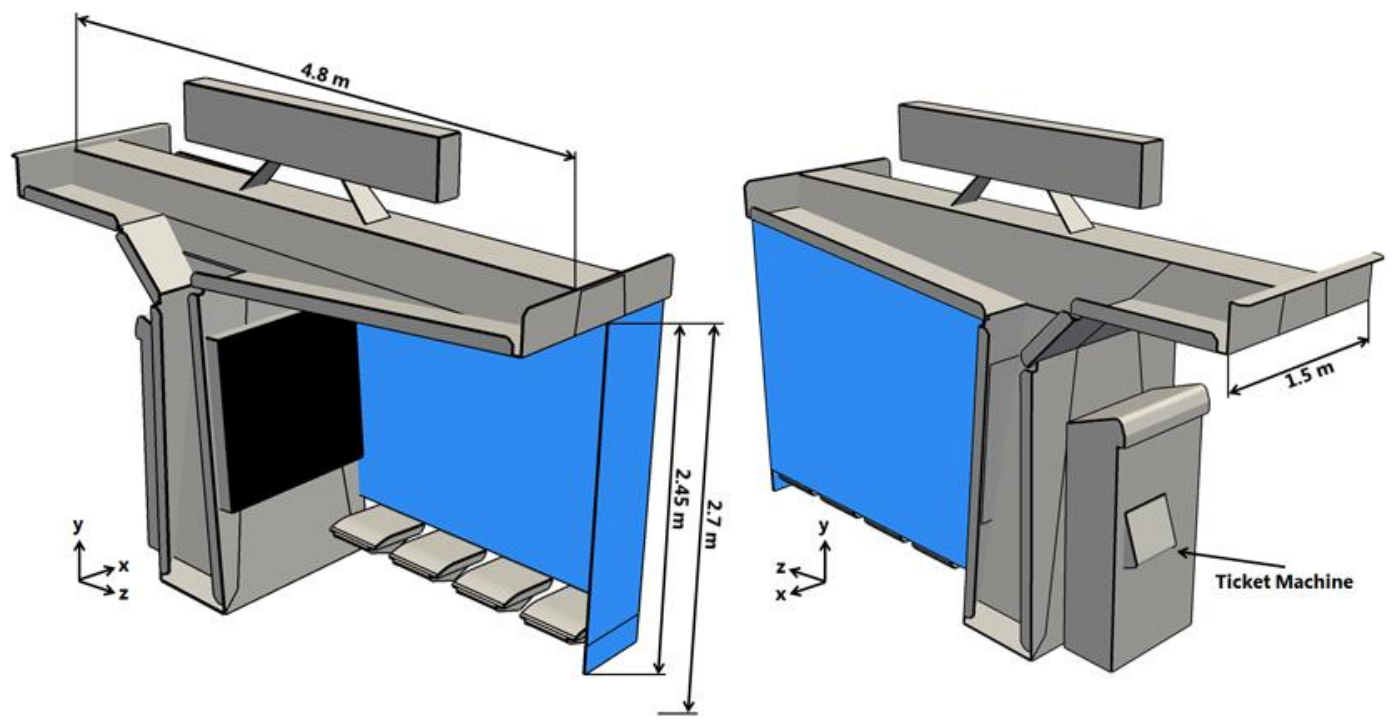

Fig. 1. Geometry and dimensions of the shelter prototype (designed by Swiss Federal Railways, SBB) viewed from two angles.

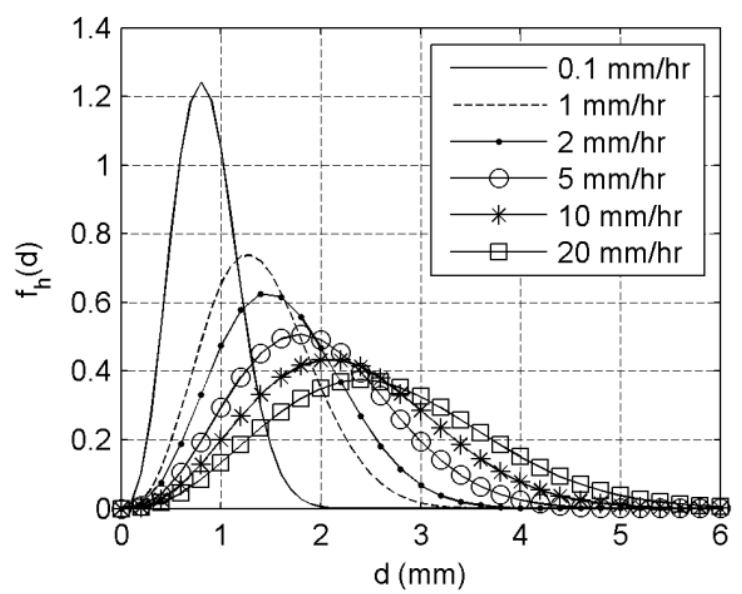

Fig. 2. Raindrop size distribution through a horizontal plane with the rainfall intensity as a parameter (Best 1950). 
a)

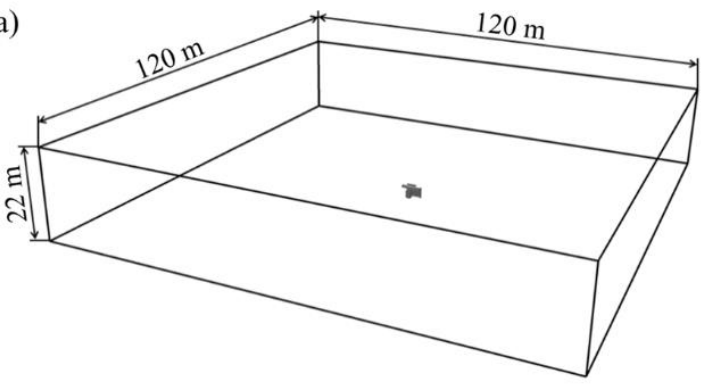

c)

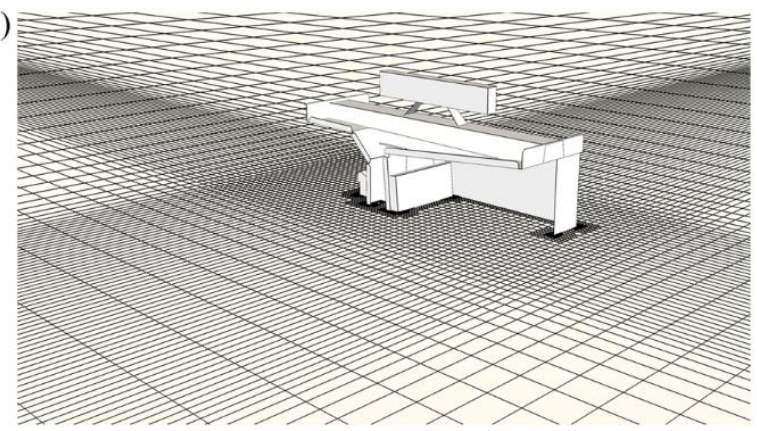

b)

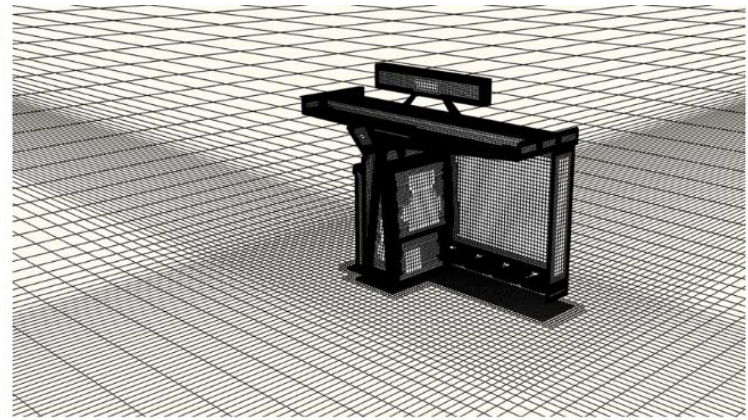

d)

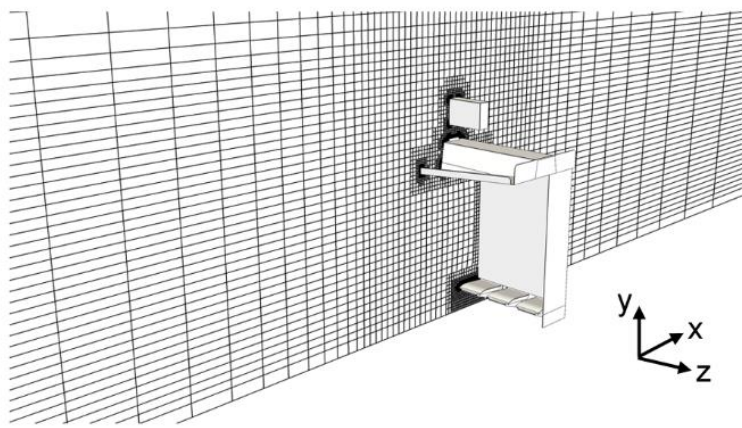

Fig. 3. a) Computational domain and b)-d) parts of the computational grid (4 542865 cells).

a)
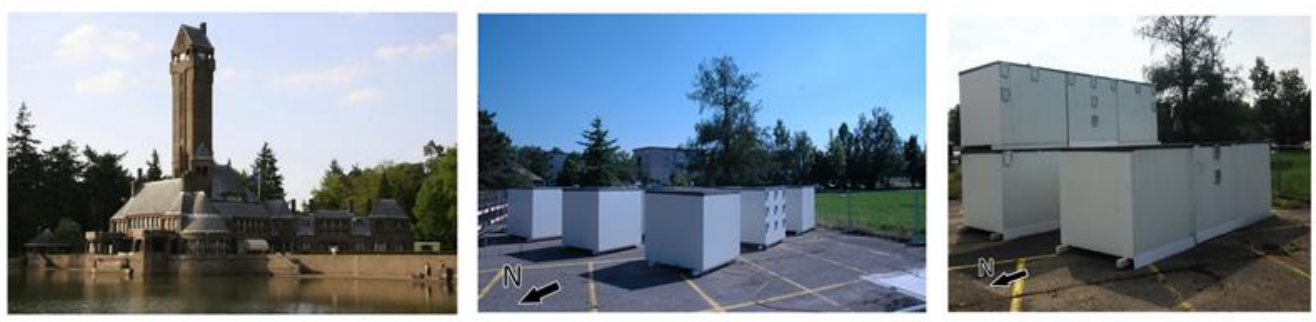

b)

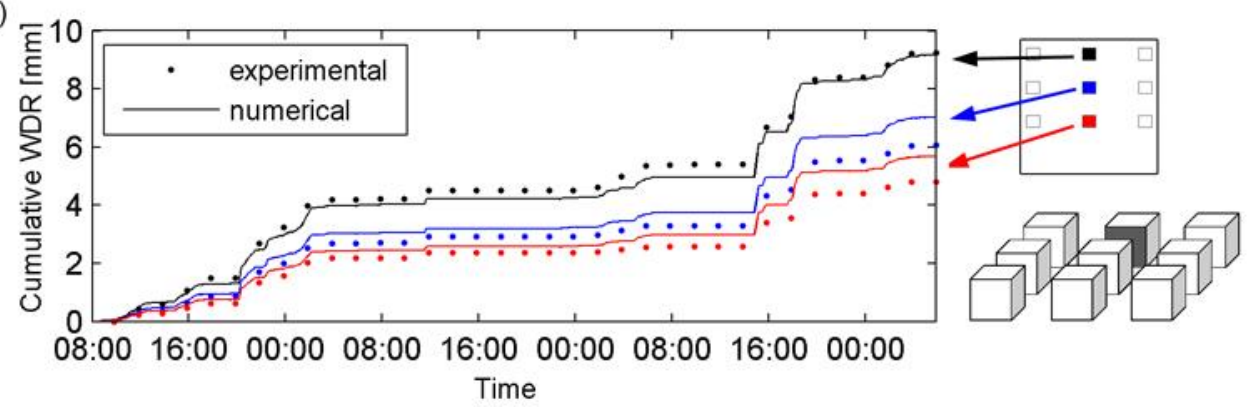

Fig. 4. a) Field measurements based on which the validation of the WDR model is performed: tower building (Briggen et al. 2009), regular array of cubic building models (Kubilay et al. 2014) and building models with different heights (Kubilay et al. 2015b). b) Comparison of the experimental and numerical cumulative WDR on the downstream cube during the rain event on September 16-19, 2013 (Kubilay et al. 2014b). 
a)
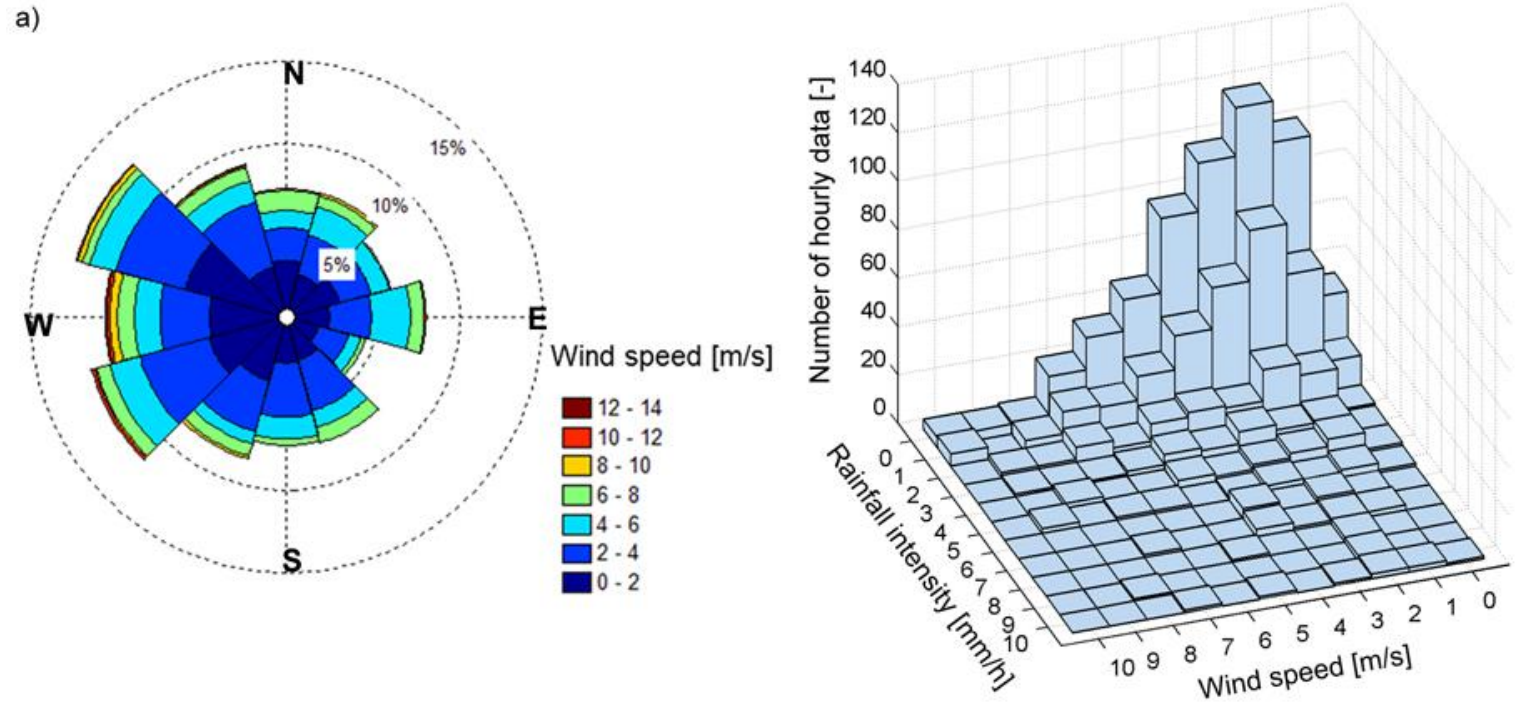

b)
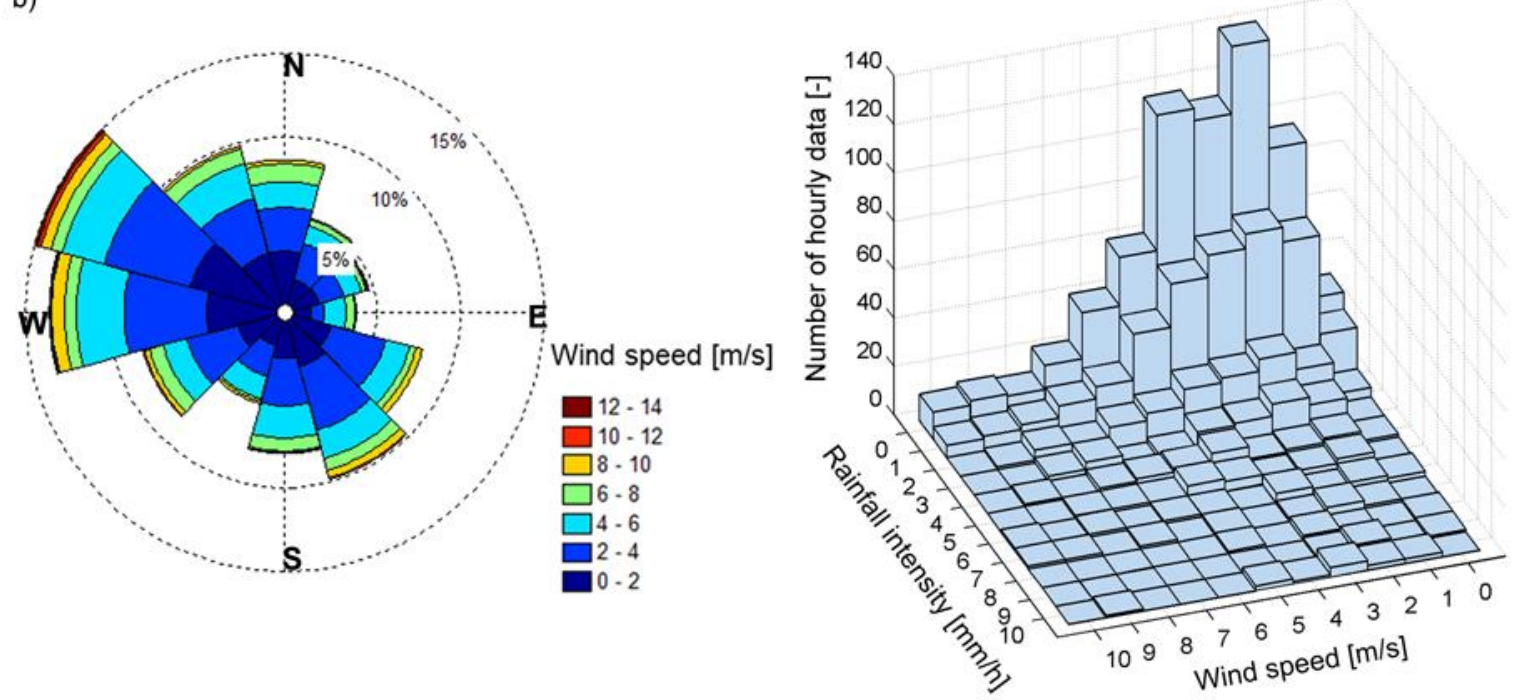

Fig. 5. Wind rose and histogram of meteorological conditions during rain based on typical meteorological year in a) Zurich and b) La Chaux-de-Fonds (Meteonorm 2000). 
a)

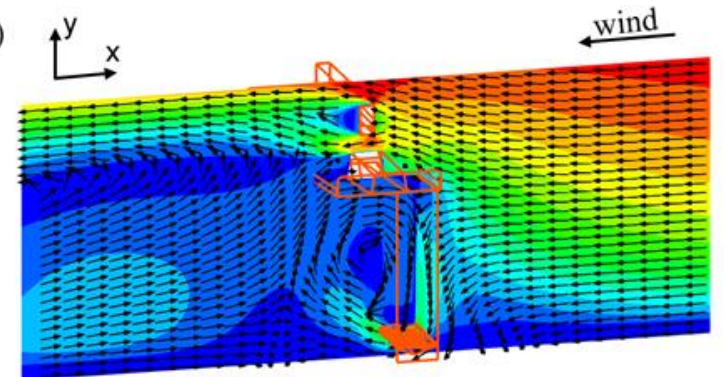

c)

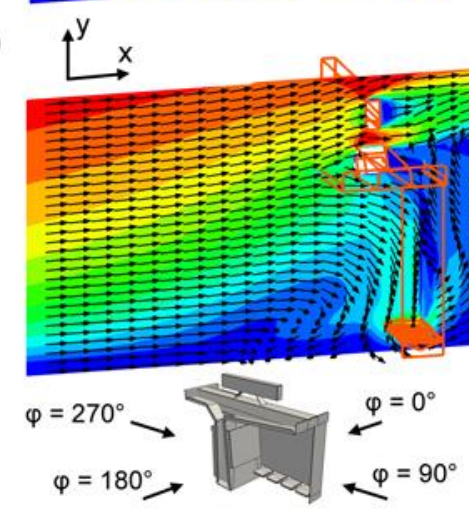

b) wind

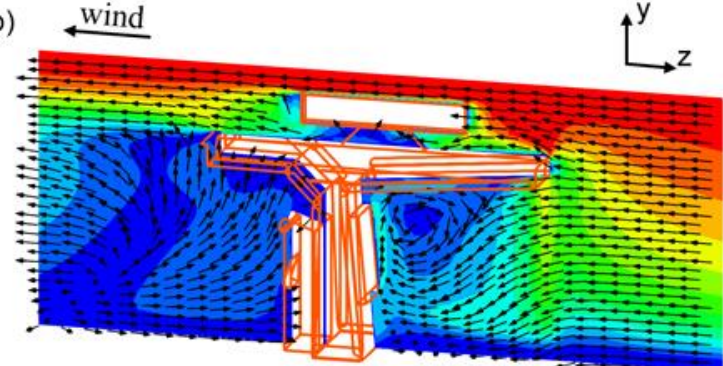

d)

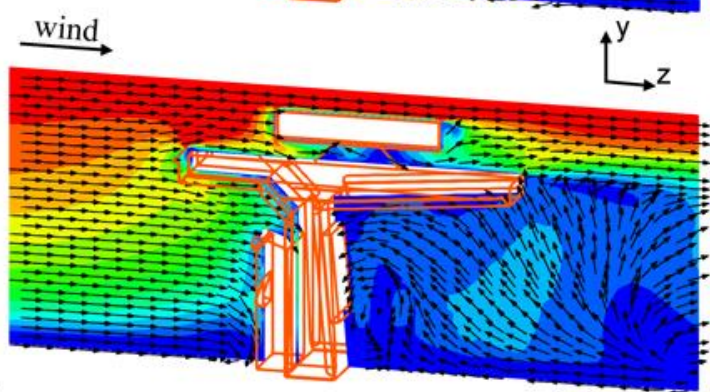

$\mathrm{U} / \mathrm{U}_{10}[-]$

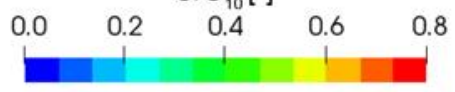

Fig. 6. Velocity vectors and contours of mean wind speed in the vertical planes for wind directions $\varphi$ of a) $0^{\circ}$, b) $90^{\circ}$, c) $180^{\circ}$ and d) $270^{\circ}$. 
a)

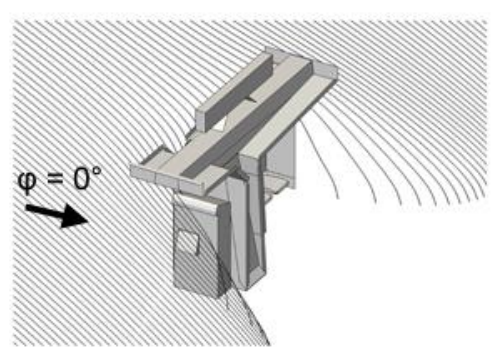

b)

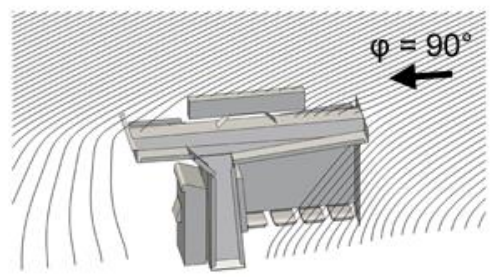

c)

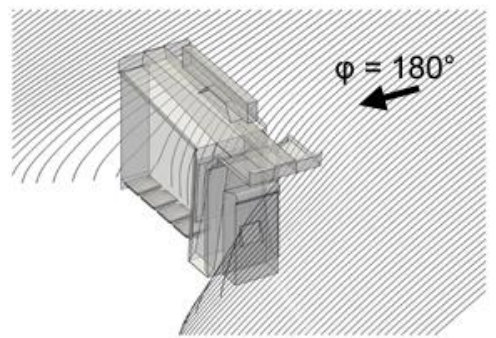

d)

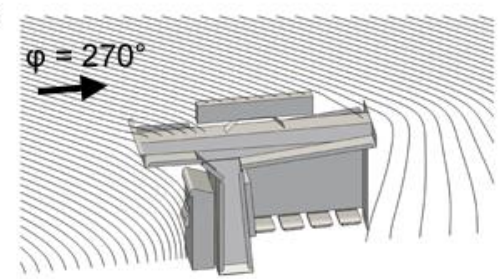

$\mathrm{d}=1.0 \mathrm{~mm}$
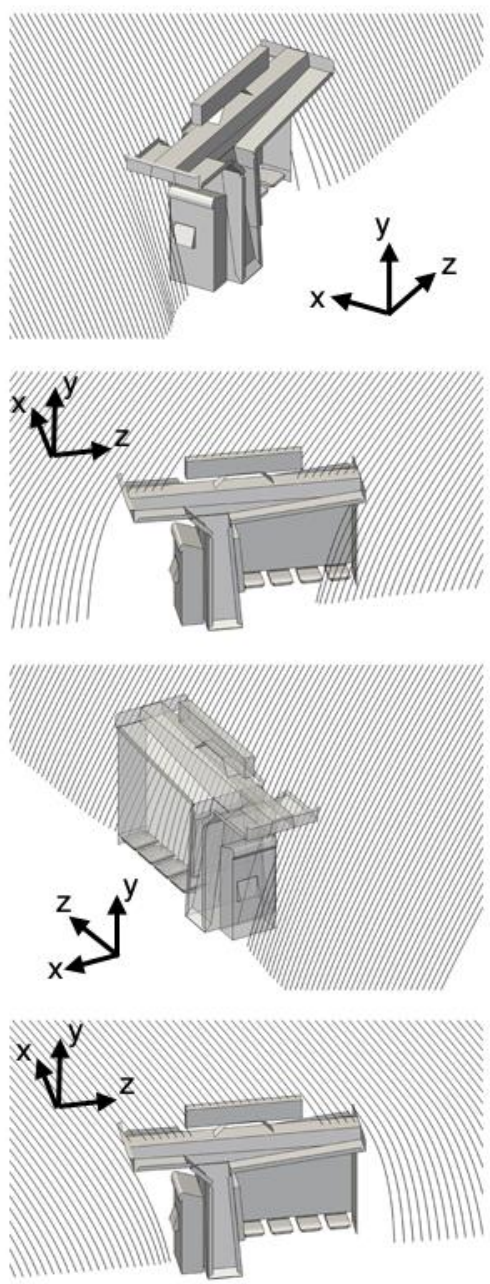

$\mathrm{d}=2.0 \mathrm{~mm}$
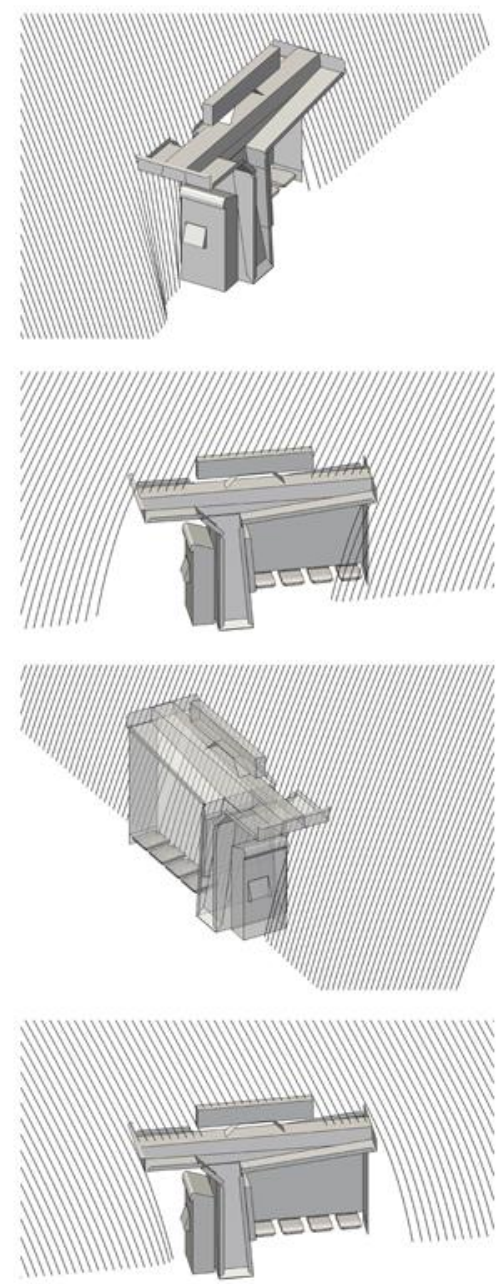

Fig. 7. Raindrop trajectories for droplet sizes of $0.3,1.0$ and $2.0 \mathrm{~mm}$ for wind directions $\varphi$ of a) $0^{\circ}$, b) $90^{\circ}$, c) $180^{\circ}$ and d) $270^{\circ}$ for a reference wind speed $U_{10}=3 \mathrm{~m} / \mathrm{s}$. 
a)

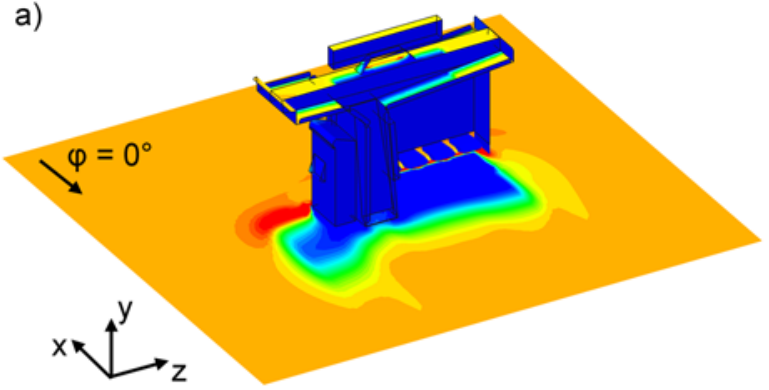

c)

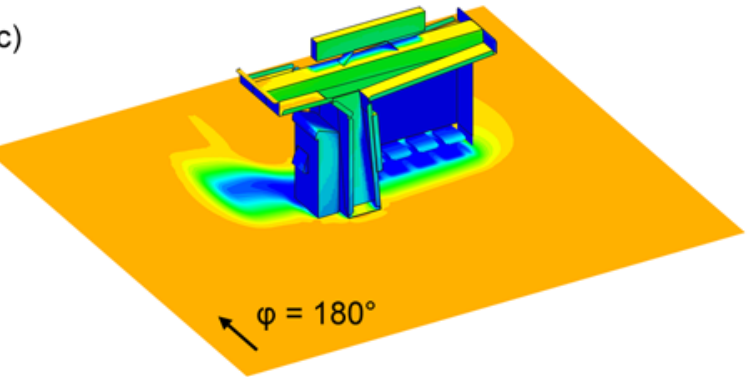

b)

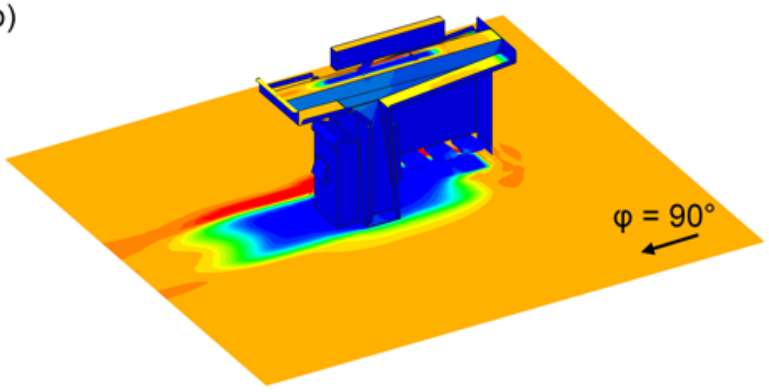

d)

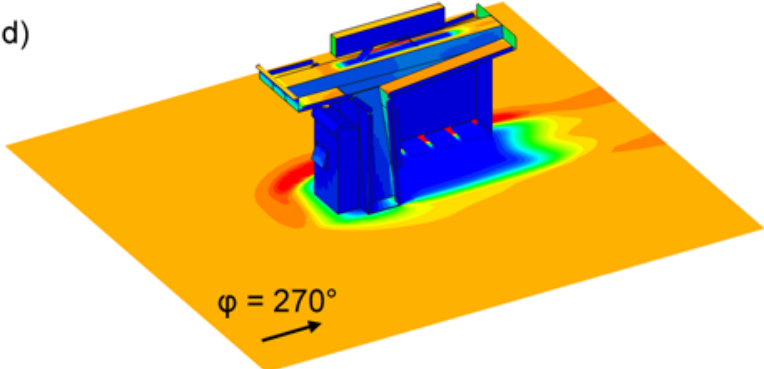

$\eta[-]$

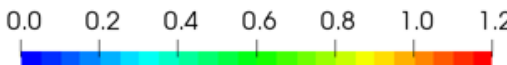

Fig. 8. Contours of catch ratio on the shelter and ground for wind directions $\varphi$ of a) $0^{\circ}$, b) $90^{\circ}$, c) $180^{\circ}$ and d) $270^{\circ}$ for reference wind speed $U_{10}=3 \mathrm{~m} / \mathrm{s}$ and rainfall intensity $R_{\mathrm{h}}=1 \mathrm{~mm} / \mathrm{h}$.

a)

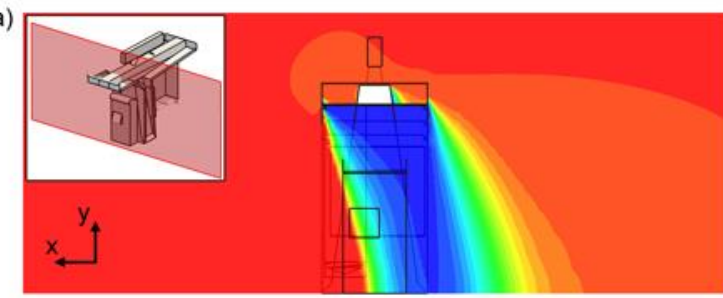

c)

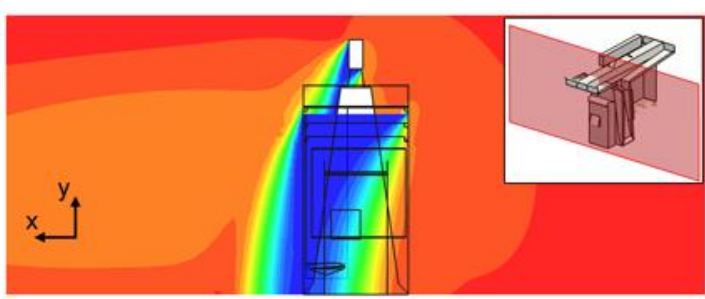

$\delta[-]$

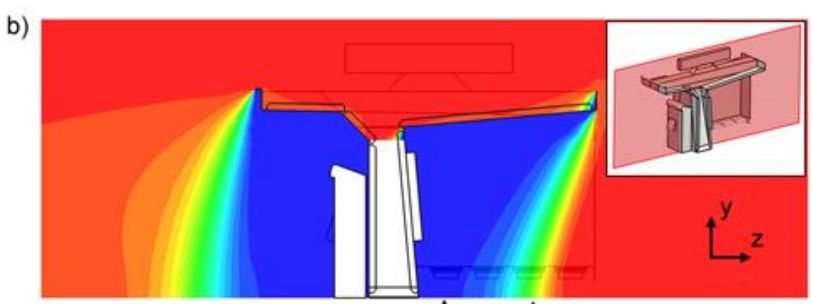

$d=0.3 \stackrel{\uparrow}{\mathrm{mm}} \mathrm{d}=\stackrel{\uparrow}{\uparrow} .0 \mathrm{~mm}$

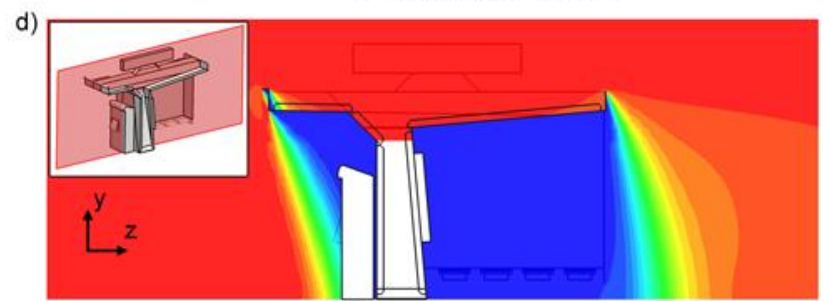

Fig. 9. Contours of exposure ratio in the vertical planes for wind directions $\varphi$ of a) $0^{\circ}$, b) $90^{\circ}$, c) $180^{\circ}$ and d) $270^{\circ}$ for reference wind speed $U_{10}=3 \mathrm{~m} / \mathrm{s}$ and rainfall intensity $R_{\mathrm{h}}=1 \mathrm{~mm} / \mathrm{h}$. 


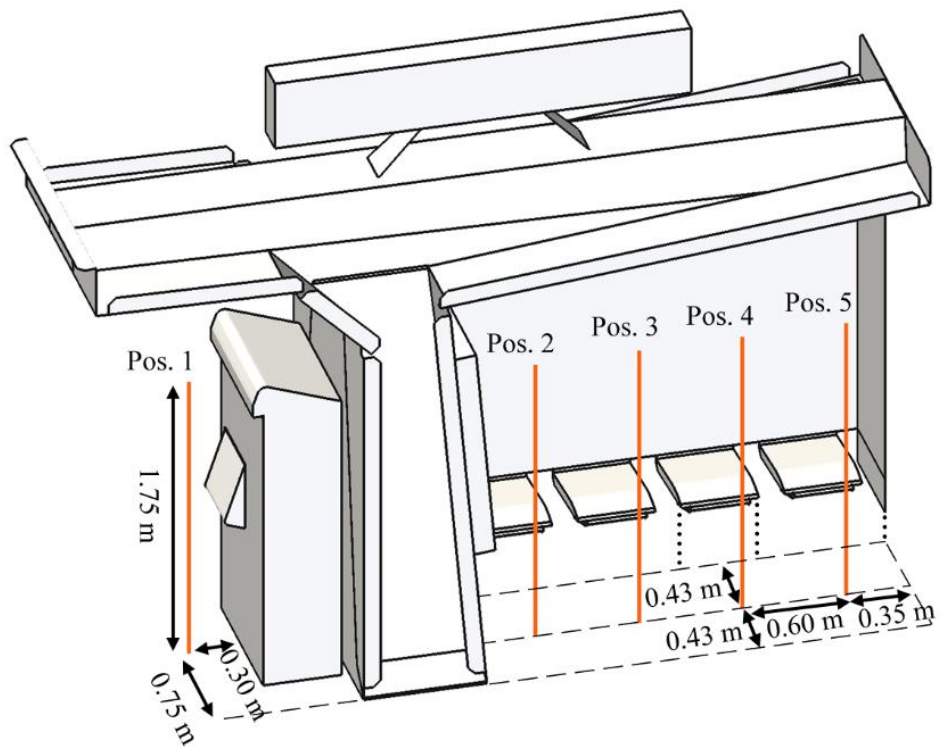

Fig. 10. Positions of the vertical lines which represent standing passengers. 


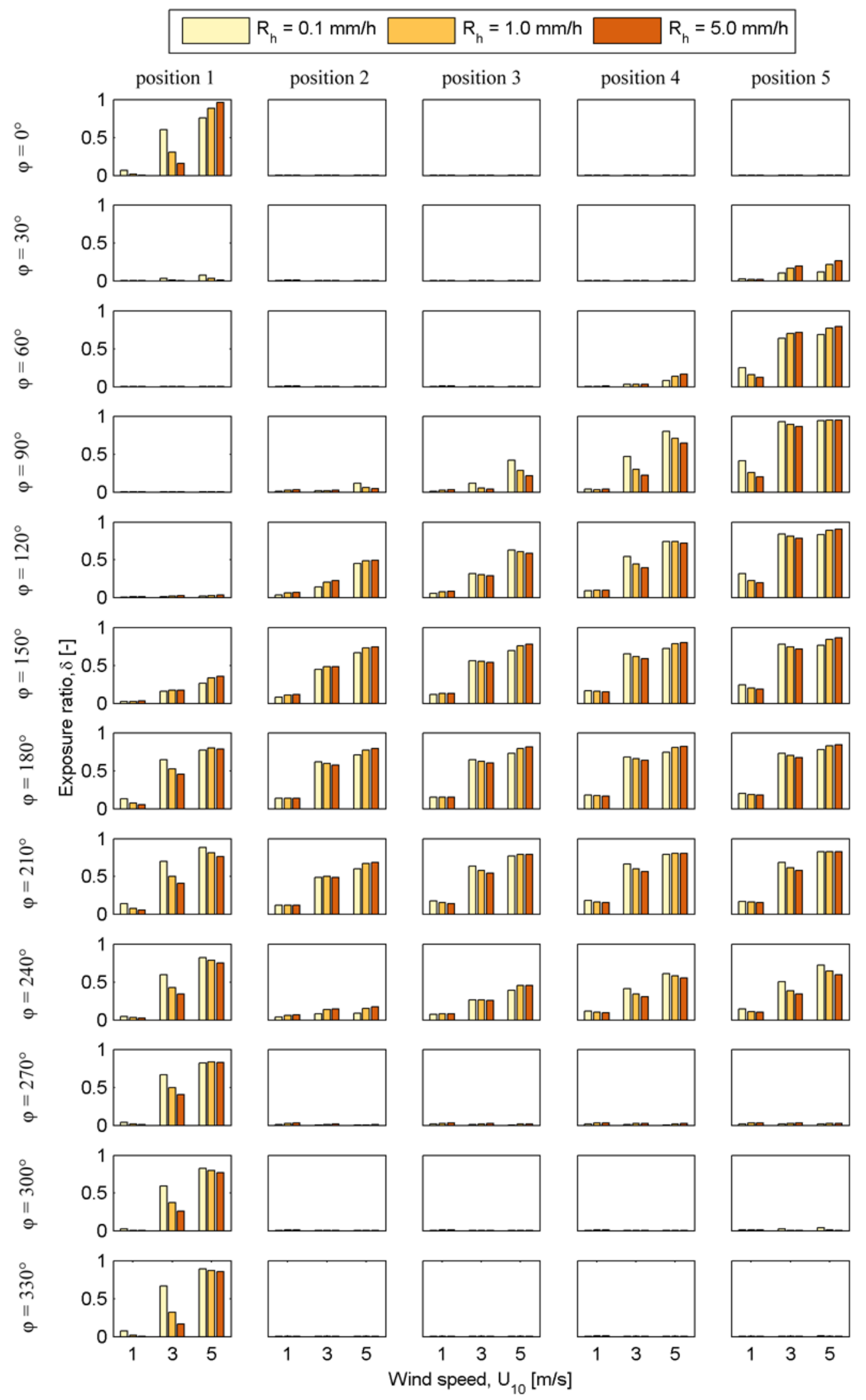

Fig. 11. Exposure ratio for wind directions $\varphi=0^{\circ}-330^{\circ}$, wind speed $1-5 \mathrm{~m} / \mathrm{s}$ and rainfall intensity $0.1-5.0 \mathrm{~mm} / \mathrm{h}$. The values are obtained by averaging along the lines for passenger positions 1 to 5 . 


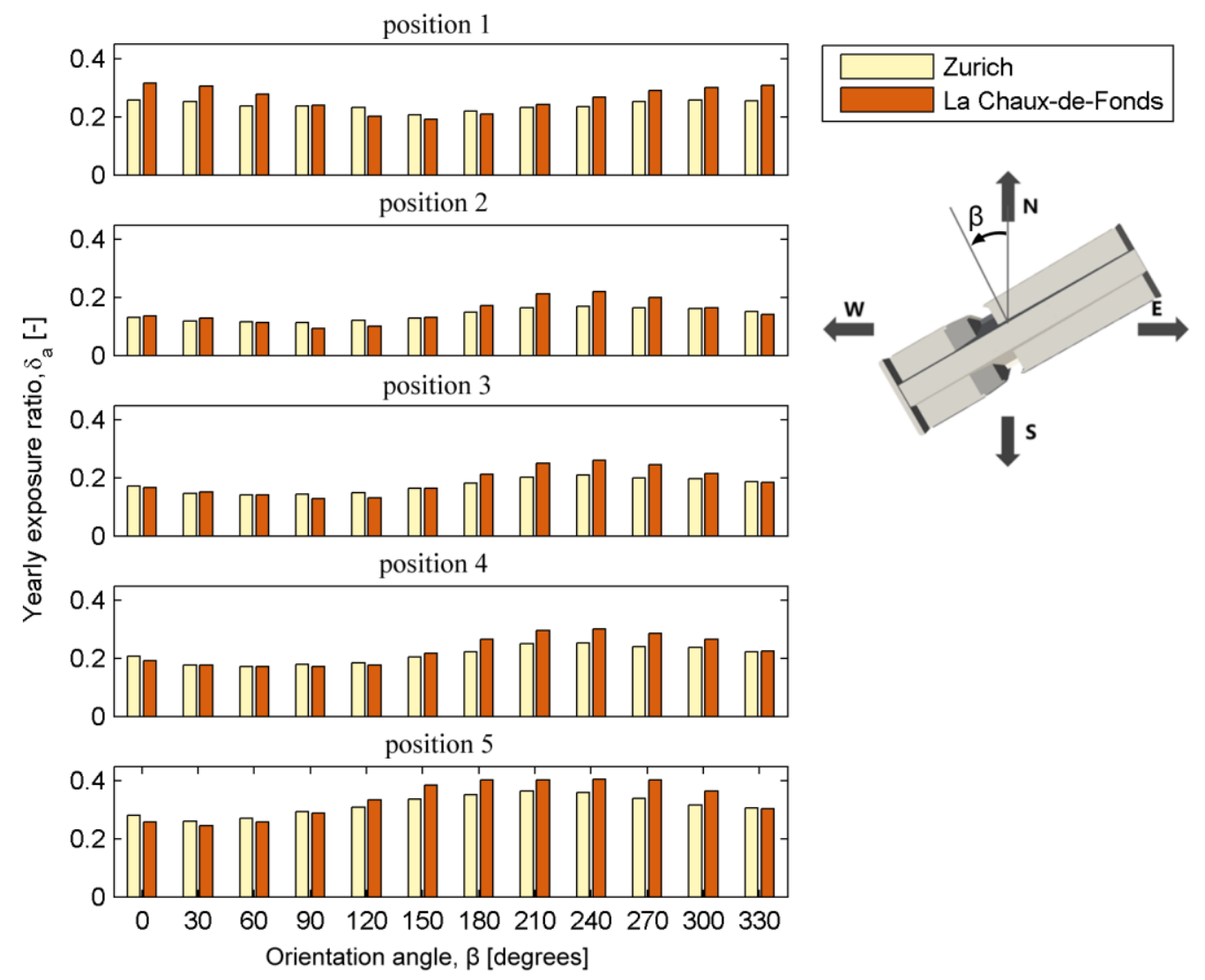

Fig. 12. Comparison of yearly exposure ratio for Zurich and La Chaux-de-Fonds at passenger positions 1 to 5.
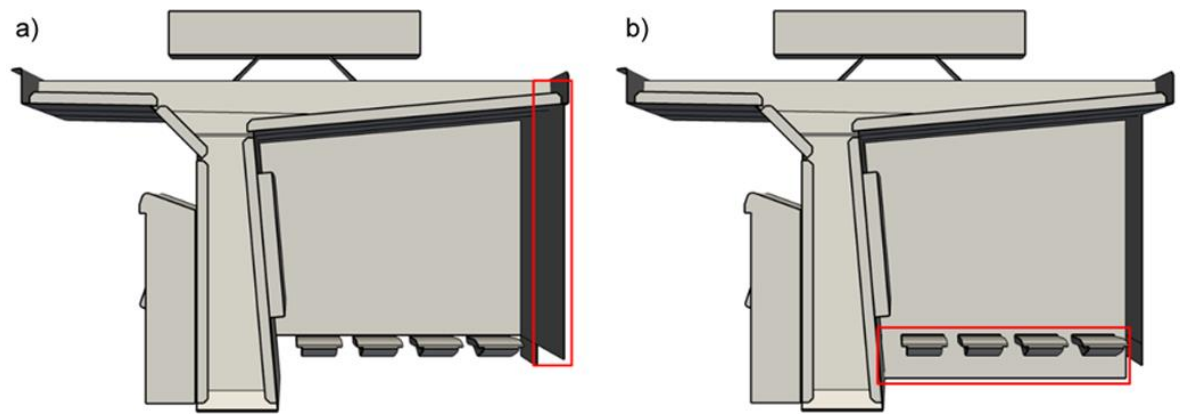

Fig. 13. Two geometrical modifications: No clearance between the ground and the back window of the shelter (left) and wider side wall (right). 


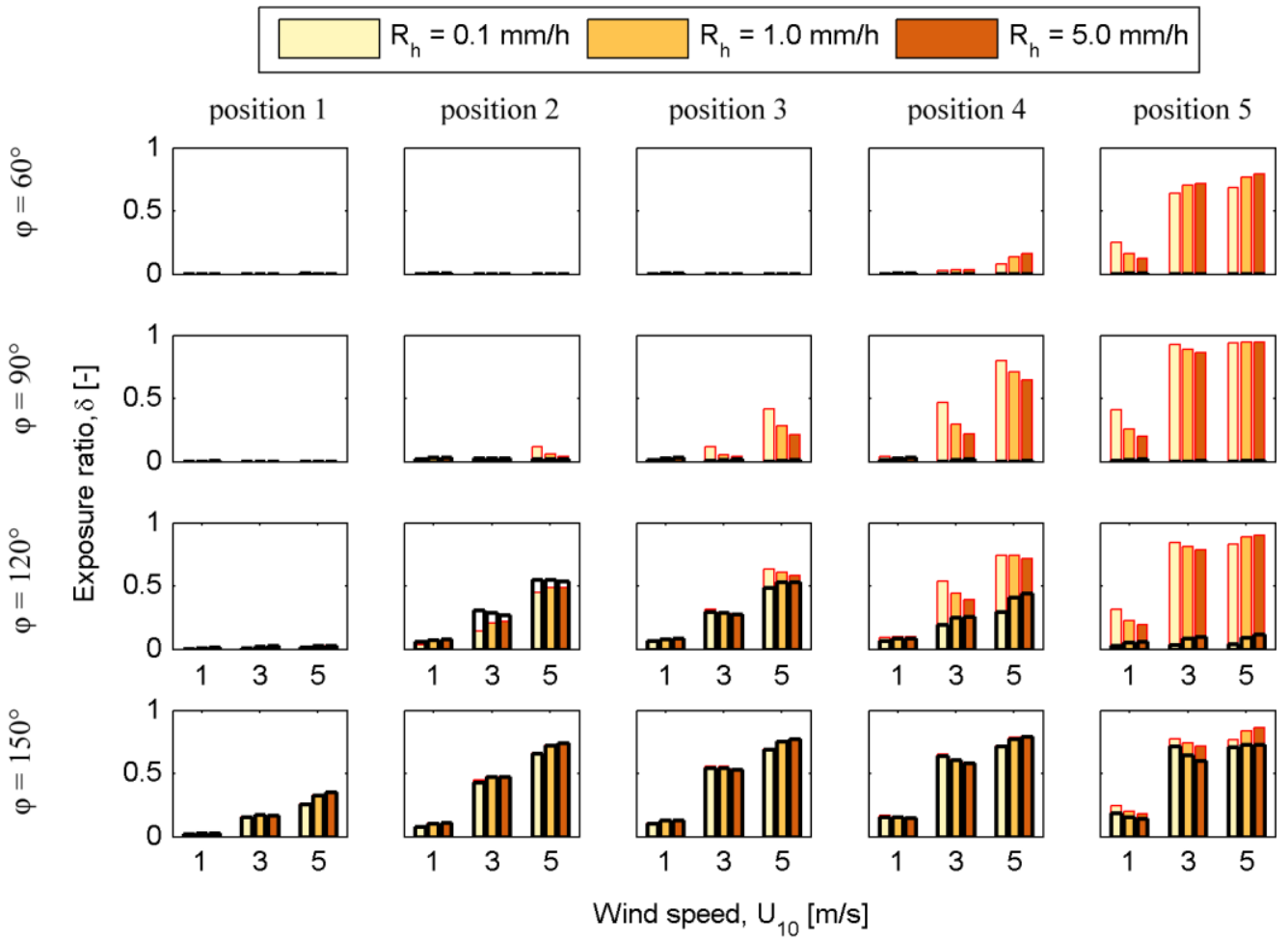

Fig. 14. Exposure ratio for passenger positions 1 to 5 before (thin red outline) and after (thick black outline) extending the side window.

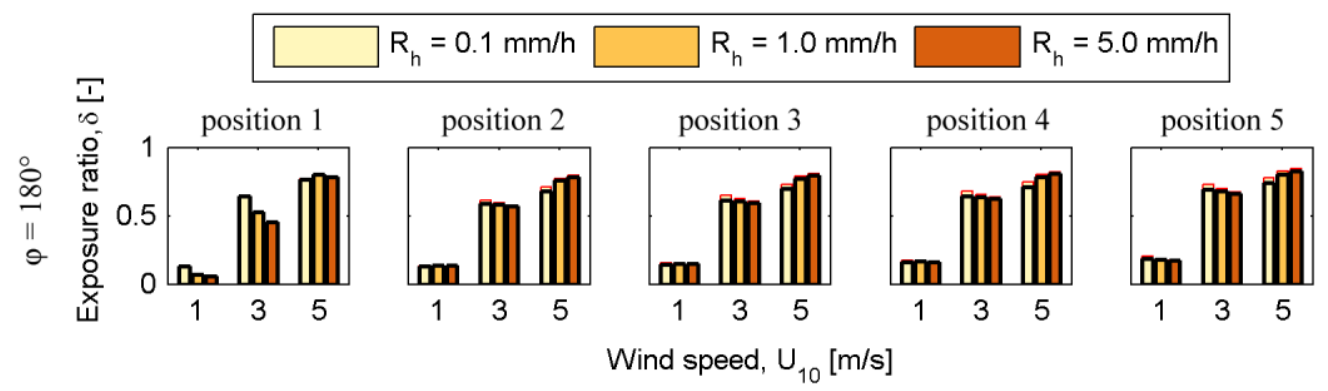

Fig. 15. Exposure ratio for passenger positions 1 to 5 before (thin red outline) and after (thick black outline) closing the clearance below the back window. 